\title{
Enhancing non-refractory aerosol apportionment from an urban industrial site through receptor modeling of complete high time-resolution aerosol mass spectra
}

\author{
M. L. McGuire ${ }^{1}$, R. Y.-W. Chang ${ }^{1,2, *}$, J. G. Slowik ${ }^{1,2, * *}$, C.-H. Jeong ${ }^{1}$, R. M. Healy ${ }^{1}$, G. Lu ${ }^{3}$, C. Mihele ${ }^{3}$, \\ J. P. D. Abbatt ${ }^{1,2}$, J. R. Brook ${ }^{3}$, and G. J. Evans ${ }^{1}$ \\ ${ }^{1}$ Southern Ontario Centre for Atmospheric Aerosol Research, University of Toronto, 200 College St., \\ Toronto, Ontario, Canada \\ ${ }^{2}$ Department of Chemistry, University of Toronto, St. George St., Toronto, Ontario, Canada \\ ${ }^{3}$ Air Quality and Research Division, Science and Technology Branch, Environment Canada, 4905 Dufferin St., \\ Toronto, Ontario, Canada \\ *now at: School of Engineering and Applied Sciences and Department of Earth and Planetary Sciences, Harvard University, \\ Cambridge, MA, USA \\ ** now at: Paul Scherrer Institute, Laboratory of Atmospheric Chemistry, General Energy Research Department, \\ Paul Scherrer Institute, Villigen, Switzerland
}

Correspondence to: G. J. Evans (greg.evans@utoronto.ca)

Received: 26 January 2014 - Published in Atmos. Chem. Phys. Discuss.: 24 February 2014

Revised: 7 June 2014 - Accepted: 30 June 2014 - Published: 13 August 2014

\begin{abstract}
Receptor modeling was performed on quadrupole unit mass resolution aerosol mass spectrometer (Q-AMS) sub-micron particulate matter (PM) chemical speciation measurements from Windsor, Ontario, an industrial city situated across the Detroit River from Detroit, Michigan. Aerosol and trace gas measurements were collected on board Environment Canada's Canadian Regional and Urban Investigation System for Environmental Research (CRUISER) mobile laboratory. Positive matrix factorization (PMF) was performed on the AMS full particle-phase mass spectrum $\left(\mathrm{PMF}_{\text {Full MS }}\right)$ encompassing both organic and inorganic components. This approach was compared to the more common method of analyzing only the organic mass spectra

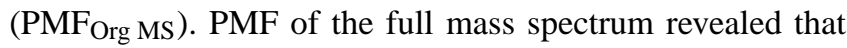
variability in the non-refractory sub-micron aerosol concentration and composition was best explained by six factors: an amine-containing factor (Amine); an ammonium sulfate- and oxygenated organic aerosol-containing factor (Sulfate-OA); an ammonium nitrate- and oxygenated organic aerosol-containing factor (Nitrate-OA); an ammonium chloride-containing factor (Chloride); a hydrocarbon-like
\end{abstract}

organic aerosol (HOA) factor; and a moderately oxygenated organic aerosol factor (OOA). PMF of the organic mass spectrum revealed three factors of similar composition to some of those revealed through $\mathrm{PMF}_{\mathrm{Full}} \mathrm{MS}$ : Amine, HOA and OOA.

Including both the inorganic and organic mass proved to be a beneficial approach to analyzing the unit mass resolution AMS data for several reasons. First, it provided a method for potentially calculating more accurate sub-micron PM mass concentrations, particularly when unusual factors are present, in this case the Amine factor. As this method does not rely on a priori knowledge of chemical species, it circumvents the need for any adjustments to the traditional AMS species fragmentation patterns to account for atypical species, and can thus lead to more complete factor profiles. It is expected that this method would be even more useful for HR-ToFAMS data, due to the ability to understand better the chemical nature of atypical factors from high-resolution mass spectra. Second, utilizing PMF to extract factors containing inorganic species allowed for the determination of the extent of neutralization, which could have implications for aerosol parameterization. Third, subtler differences in organic aerosol 
components were resolved through the incorporation of inorganic mass into the PMF matrix. The additional temporal features provided by the inorganic aerosol components allowed for the resolution of more types of oxygenated organic aerosol than could be reliably resolved from PMF of organics alone. Comparison of findings from the $\mathrm{PMF}_{\mathrm{Full}} \mathrm{MS}$ and $\mathrm{PMF}_{\mathrm{Org}} \mathrm{MS}$ methods showed that for the Windsor airshed, the PMF Full MS method enabled additional conclusions to be drawn in terms of aerosol sources and chemical processes. While performing $\mathrm{PMF}_{\text {Org MS }}$ can provide important distinctions between types of organic aerosol, it is shown that including inorganic species in the PMF analysis can permit further apportionment of organics for unit mass resolution AMS mass spectra.

\section{Introduction}

Atmospheric aerosol or particulate matter (PM) is known to have important implications for atmospheric visibility (Watson, 2002), climate change (IPCC, 2013), and human health (Pope and Dockery, 2006; Anderson et al., 2012; Brook et al., 2010). Understanding the sources and processes responsible for PM composition and concentration is critical to enacting effective PM reduction strategies. Receptor modeling of PM chemical speciation data is one method towards achieving this. Historically, receptor modeling studies have focused on understanding integrated filter measurements, which have been particularly useful for providing an overview of the main chemical components of major source categories and their longer-term temporal trends (Gordon, 1980; Hopke, 2003; Watson et al., 2008). More recently, receptor modeling analyses have been focused on online high time-resolution chemical analysis techniques, as they can provide additional insight into sources and processes not captured by the chemical or temporal resolution of daily filter measurements.

Aerosol mass spectrometry is among the most widely used high-time resolution PM chemical speciation methods that can be used to quantify the impacts of non-refractory source components, including both organic and inorganic components. Receptor modeling using positive matrix factorization (PMF) has become a useful analytical technique for further understanding the origins of AMS-measured aerosol. Among these studies, most have focused on the organic fraction of the AMS mass spectrum (e.g., Lanz et al., 2007; Ulbrich et al., 2009) in an effort to resolve uncertainty regarding the sources and processes contributing to secondary organic aerosol (SOA), an aerosol component with potential implications for climate (IPCC, 2013). Many of these studies have focused on the application of factor analysis to the organic mass fraction in an attempt to deconvolve it into descriptive sub-components, namely a hydrocarbon-like organic aerosol (HOA) factor, and an oxygenated organic aerosol (OOA) factor. Examination of data sets from numerous, diverse environments has shown that the OOA fraction often splits into two sub-components, OOAI and OOAII (Zhang et al., 2011). Observations of their temporal behavior have shown that these two factors typically exhibit different volatility regimes, whereby OOAII exhibits significant diurnal variability associated with condensation and volatilization from temperature cycling, and, by contrast, OOAI has been mainly associated with synoptic flow regimes, with no significant association with temperature cycling. The semi-volatile OOAII type factor was first reported in a study by Lanz et al. (2007), although its volatile nature was first substantiated with external measurements in a study by Huffman et al. (2009); in the latter study it was shown that decreased volatility of OA factors was associated with increasing oxygenation or oxygen to carbon (O/C) ratio (Huffman et al., 2009). As a result, the OOAI and OOAII factors are often referred to in the literature as low-volatility OOA (LV-OOA), and semi-volatile OOA (SV-OOA), respectively (Jimenez et al., 2009). While the HOA and OOA components have been the most widely observed organic components deconvolved in the multitude of AMS studies performed to date (Zhang et al., 2007), other factors have been identified, such as biomass burning organic aerosol (BBOA) (e.g., Aiken et al., 2009), amine-containing organic aerosol (e.g., Aiken et al., 2009; Sun et al., 2012; Docherty et al., 2011; Hildebrandt et al., 2011), and even cooking organic aerosol (COA) (e.g., Lanz et al., 2007; Allan et al., 2010; Sun et al., 2011; Mohr et al., 2012; Crippa et al., 2013a). In many studies, correlation analysis of organics with inorganic species has been used for further ascertaining the sources and processes contributing to a particular factor. For instance, significant correlations have been found between OOAI and $\mathrm{SO}_{4}^{2-}$, and between OOAII and $\mathrm{NO}_{3}^{-}$(Lanz et al., 2007; Ulbrich et al., 2008).

This study presents a receptor modeling analysis of high time-resolution unit mass resolution quadrupole AMS measurements. Aerosol and trace gas speciation measurements were made on board Environment Canada's CRUISER (Canadian Regional and Urban Investigation System for Environmental Research) mobile laboratory at MicMac Park in Windsor, Ontario in the winter of 2005. A different approach was taken in this study with respect to the majority of previous receptor modeling analyses of the non-refractory submicron chemical composition, as PMF was applied to the full mass spectrum, comprising both the organic and inorganic components. To the authors' knowledge, combined PMF analysis of organic and inorganic AMS mass spectra has been performed in only three other studies (Chang et al., 2011; Sun et al., 2012; Crippa et al., 2013b). Of these, the study by Sun et al. (2012) was the only one to include all inorganic and organic species together. While PMF had previously been applied to data including AMS-derived bulk concentrations of inorganic and organic species (e.g., Buset et al., 2006; Crippa et al., 2013b), Chang et al. (2011) were the first to apply the PMF multivariate deconvolution algorithm to combined 


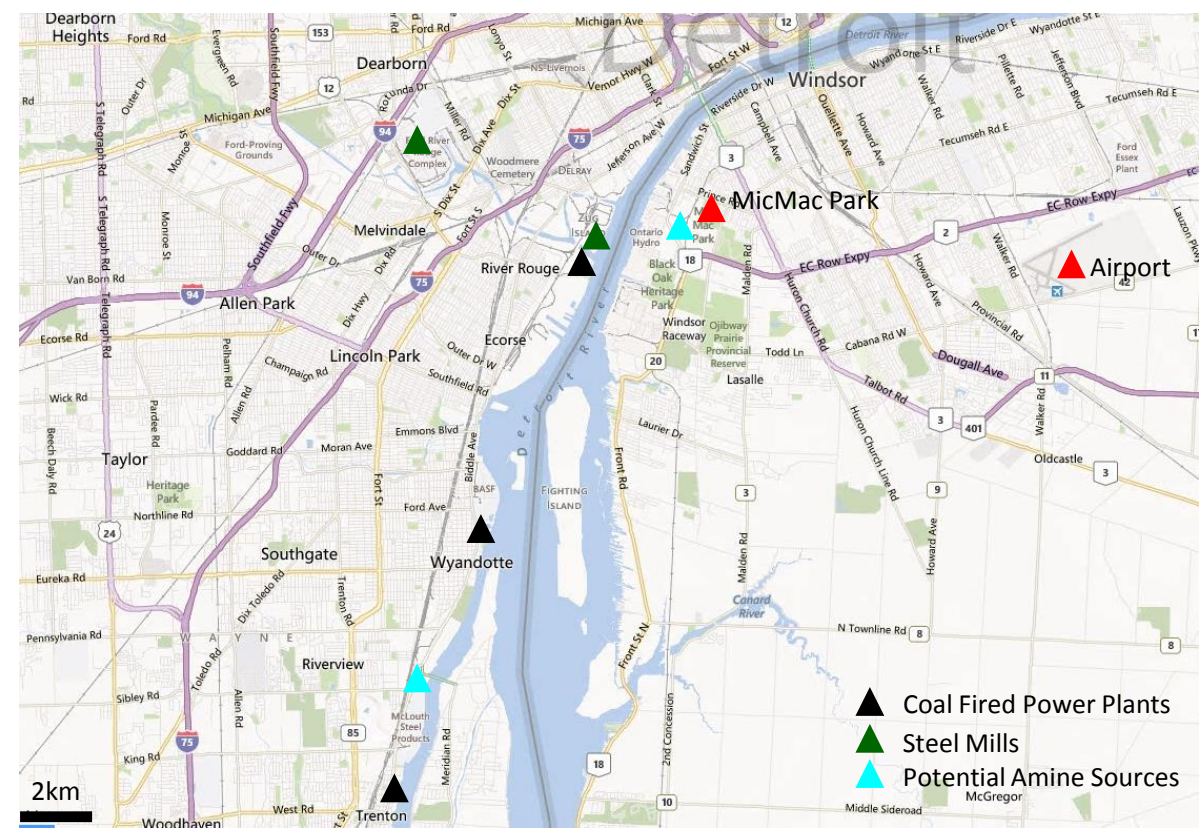

Figure 1. The location of the sampling site (MicMac Park) in Windsor, Ontario relative to major industrial sources, namely coal-fired power plants, steel mills, and potential large amine sources. It can be seen that the measurement site was located close to the largest international border crossing between the US and Canada (Huron Church Road and the Ambassador Bridge).

organic and inorganic mass spectra, in that case to ambient Arctic aerosol (Chang et al., 2011). However, low ambient aerosol concentrations, and low associated signal-to-noise ratios, prevented the inclusion of all species in the analysis. As a result, $\mathrm{NH}_{4}^{+}$was excluded, which precluded certain conclusions regarding aerosol neutralization from being drawn. Nonetheless, four factors were extracted in that study, including factors representing marine biogenic emissions (containing methanesulfonic acid or MSA), continental emissions, ship emissions, and OOA. Each factor was characterized by differing degrees of cross-apportionment between organic and inorganic species. Eight factors were identified in the study by Sun et al., many more than found in the Arctic study, mainly due to the urban sampling location in New York City (Sun et al., 2012). Similar to Chang et al. (2011), significant organic and inorganic cross-apportionment was noted for most of the factors. In the study by Crippa et al. (2013b), only $\mathrm{SO}_{4}^{2-}$-related ions were included in the PMF analysis in addition to organics, which allowed for the apportionment of $\mathrm{SO}_{4}^{2-}$ ions to marine and terrestrial aerosol factors (Crippa et al., 2013b).

This study focuses on the physical interpretation of crossapportionment between organic and inorganic non-refractory sub-micron PM species between factors. Drawing upon cold condition measurements from a complex, industrialized site, this analysis illustrates how this methodology can help to understand underlying aerosol sources and processes better, and to identify new scientific and methodological conclusions.

\section{Experimental methods}

\subsection{Aerosol mass spectrometer measurements}

Aerosol and trace gas measurements were collected on board Environment Canada's CRUISER mobile laboratory, which was stationed at MicMac Park in Windsor $\left(42^{\circ} 17^{\prime} 5.38^{\prime \prime} \mathrm{N}\right.$, $83^{\circ} 4^{\prime} 31.42^{\prime \prime} \mathrm{W}$ ) in January and early February 2005. Located next to Detroit on the Canada-US border in southwestern Ontario, Windsor has historically been known to experience frequent episodes of poor air quality. Local sources of PM are numerous and diverse due to a large manufacturing base, including sources such as steelmaking, salt and gypsum mining, petrochemical refining, and coal-fired power generation. Another significant local source is traffic, given that the Windsor-Detroit border crossing is the largest international border crossing between Canada and the US. Regionally, Windsor is impacted by many sources, but perhaps most significantly by coal-fired power plants to the south in the Ohio River valley. A map of the Windsor-Detroit area is shown in Fig. 1.

Chemical speciation measurements of sub-micron PM were made on board CRUISER using a unit mass resolution quadrupole aerosol mass spectrometer (Q-AMS) (Aerodyne Research Inc., Billerica, MA, USA). The AMS sampled from 12 January to 2 February 2005, except for a period between 15 and 18 January, when it was not operating. Sampling occurred at a 15 min time resolution, except for a short period at the beginning of the campaign (12 to 13 January), when it sampled at a $5 \mathrm{~min}$ time resolution. CRUISER samples 
air at $4 \mathrm{~m}$ a.g.l. (above ground level) through a $\mathrm{PM}_{2.5}$ sharp cut cyclone (Rupprecht and Patashnick, East Greenbush, NY, USA) at a flow rate of $16.7 \mathrm{Lpm}$ (litre per minute), to supply a primary sampling line from which several onboard PM and gas instruments are connected. The temperature in the sampling enclosure in wintertime is approximately $20^{\circ} \mathrm{C}$, although sheath air surrounding the primary $1.25^{\prime \prime}$ diameter stainless steel sampling line maintains it at near-ambient temperature. The AMS is connected to CRUISER's primary sampling line by $0.8 \mathrm{~m}$ of conductive tubing, and samples at a flow rate of $1 \mathrm{Lpm}$. Although the aerosol was not dried prior to AMS sampling, the relative humidity $(\mathrm{RH})$ remained close to that of the ambient air due to the use of sheath air and a relatively short sampling line. Filtered AMS measurements were performed at several times during the campaign, and were removed from the data set, resulting in 1745 observations. The operating principles of the AMS instrument have been documented elsewhere (Jayne et al., 2000; Canagaratna et al., 2007b), although those of the Q-AMS are briefly outlined here. Particles are sampled through the particle inlet and focused into a collimated beam using an aerodynamic lens. The stream of particles impact a porous tungsten surface heated to $\sim 600^{\circ} \mathrm{C}$, whereupon the non-refractory components of the particles flash vaporize. The resulting gases are ionized by electron impact $(\mathrm{EI}, 70 \mathrm{eV})$, and the resulting ions are measured using a quadrupole mass spectrometer.

The AMS was calibrated for ionization efficiency by atomizing an $\mathrm{NH}_{4} \mathrm{NO}_{3}$ solution and then size-selecting $300 \mathrm{~nm}$ particles using a TSI 3071 electrostatic classifier. A relative ionization efficiency (vs. $\mathrm{NO}_{3}^{+}$) of 4.5 for $\mathrm{NH}_{4}^{+}$was required to obtain ion balance for the bulk $\mathrm{NH}_{4} \mathrm{NO}_{3}$ calibration particles, and this value was applied to the ambient data. Default relative ionization efficiencies were assumed for organics (1.4), chloride (1.3), nitrate (1.1), and sulfate (1.2).

The collection efficiency of the AMS is often estimated by comparison of the measured mass with that of a collocated instrument. If collocated external $\mathrm{PM}_{1}$ mass measurements are unavailable, collection efficiency (CE) is often assumed by comparison of the combined AMS sub-micron PM mass and $\mathrm{BC}$ with an external measure of $\mathrm{PM}_{2.5}$. Middlebrook et al. (2012) have also shown that a composition-dependent CE can be estimated from the bulk aerosol composition (Middlebrook et al., 2012). These two options were investigated to determine whether a CE other than a default of 1 could be applied to the data, and the results of this investigation are presented in the Supplement. Ultimately, this analysis did not yield a reliable estimate of $\mathrm{CE}$, as such no correction was applied to these data, and a default, simple integer collection efficiency of unity was assumed for this campaign. This value has been used in other studies (Lanz et al., 2007; Richard et al., 2011; Chirico et al., 2011), and reflects a lower bound for the non-refractory mass concentration. While an accurate estimate of collection efficiency is required for overall mass determination, it remains a multiplier (either constant, or composition dependent) applied to the total mass concentration, and ultimately does not affect the primary study conclusions with respect to identifying and characterizing factors.

The time series of collected AMS mass spectra were separated into chemically resolved mass spectra $\left(\mathrm{NH}_{4}^{+}, \mathrm{NO}_{3}^{-}\right.$, $\mathrm{SO}_{4}^{2-}, \mathrm{Cl}^{-}$, and organics) using pre-defined fragmentation patterns (Allan et al., 2004), as implemented in the Deluxe v1.43 Q-AMS analysis software for the IGOR Pro software package (Wavemetrics, Inc.).

\subsection{Positive matrix factorization}

Positive matrix factorization or PMF (Paatero and Tapper, 1993, 1994; Paatero, 1997) is a non-negative factor analysis model that can be used to represent a time series of measurements as a linear combination of static factor profiles (ideally corresponding to specific sources and/or processes) and their time-dependent intensities. It is applied to an $n \times m$ matrix of data, $X$, and solves the general receptor equation

$x_{i j}=\sum_{k=1}^{p} g_{i k} f_{k j}+e_{i j}$,

where $n$ is the number of samples and $m$ is the number of species; $x_{i j}$ is the concentration of the $j$ th species in the $i$ th sample; $g_{i k}$ is the contribution of the $k$ th factor to the $i$ th sample; $f_{k j}$ is the mass fraction of the $j$ th species contributing to the $k$ th factor; $e_{i j}$ is the residual concentration of the $j$ th species in the $i$ th sample; and $p$ is the number of independent factors as chosen by the user. The general receptor equation is solved iteratively, using a Gauss-Newton, weighted least squares algorithm, until the object function $Q$ is minimized:

$$
Q=\sum_{i=1}^{n} \sum_{j=1}^{m}\left(\frac{e_{i j}}{s_{i j}}\right)^{2},
$$

where $s_{i j}$ is an element in the $n \times m$ matrix, $\mathbf{S}$, of uncertainties corresponding to $x_{i j}$. The expected $Q$ value is defined as

$Q_{\text {expected }}=n m-p(n+m)$.

PMF analysis was performed using EPA PMF 4.1 (Norris et al., 2010). Two different approaches were taken in this study. One approach involved application of PMF to the organic mass spectra only ( $\left.\mathrm{PMF}_{\mathrm{Org}} \mathrm{MS}\right)$, and the other involved application of PMF to the full mass spectra $\left(\mathrm{PMF}_{\text {Full MS }}\right)$. As such, two different methodologies were required for data pretreatment, and formulation of the data and error matrices.

The data and error matrices for the $\mathrm{PMF}_{\mathrm{Org}} \mathrm{MS}$ analysis were prepared following principles outlined in Ulbrich et al. (2009). A total of $167 \mathrm{~m} / z$ were included in the PMF $_{\text {Org MS }}$ analysis $(m / z 12-200)$, with $m / z$ excluded due to either a low signal (e.g., 19-23), a signal dominated by inorganic (e.g., 4) or gaseous (e.g., 28) species, or high background levels (e.g., 149) (Ulbrich et al., 2009; Zhang et al., 
2005). Uncertainties for the $\mathrm{PMF}_{\mathrm{Org}} \mathrm{MS}$ analysis were calculated according to the method of Allan et al. (2003), and a minimum error corresponding to the counting of a single ion was enforced throughout the data set (Ulbrich et al., 2009). Within the AMS organic fraction extraction process, certain $m / z(16,17,18$, and 44$)$ are assumed to be a constant fraction of $m / z 44$. The uncertainties in these ions were accordingly multiplied by $\sqrt{4}$ to prevent them from being overweighted by the PMF algorithm. The signal-to-noise ratio $(S / N)$ for each $m / z$ was calculated to identify weak $(0.2<S / N<2)$, and bad $(S / N<0.2)$ variables; a downweighting policy was applied such that weak variables are downweighted by a factor of 2, and bad variables excluded. No variables were designated as bad for this analysis.

The data and error matrices for the $\mathrm{PMF}_{\text {Full MS analy- }}$ sis were prepared following principles outlined by Chang et al. (2011). The data matrix was calculated in nitrate equivalent $\left(\mathrm{NO}_{3 \text { eq }}\right)$ mass (refer to Sect. 2.3) and calculated by taking the entire raw MS matrix ("All") and from it, subtracting the mass spectral matrices of species not of interest to the analysis (i.e., air and water), leaving the contributions from fragments associated with $\mathrm{NH}_{4}^{+}, \mathrm{NO}_{3}^{-}, \mathrm{SO}_{4}^{2-}$, $\mathrm{Cl}^{-}$, and organics. Downweighting of selective organic or inorganic peaks as is required when conducting the $\mathrm{PMF}_{\mathrm{Org}} \mathrm{MS}$ analysis was not required in the $\mathrm{PMF}_{\text {Full MS analysis, as }}$ the $\mathbf{P M F}_{\text {Full MS }}$ matrix resulted from the subtraction of the "Air" and "Water" components from the original "All" ma-

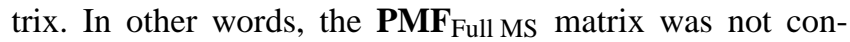
structed from application of the fragmentation scheme to create "Org", " $\mathrm{SO}_{4}^{2-}$ ", " $\mathrm{NO}_{3}^{-}$", "Chl", and " $\mathrm{NH}_{4}^{+}$" matrices, which could be added together to generate a "Full MS" matrix, but was a result of the subtraction of the "Air" and "Water" components subtracted from the original "All" matrix. The corresponding error matrix (in $\mathrm{NO}_{3 \text { eq }}$ mass) was then constructed by adding in quadrature the "All_err", "Water_err", and "Air_err" matrices. Similar to the organic matrix preparation, a minimum uncertainty corresponding to a single ion was enforced, and the same $S / N$ policy was applied, although no variables were designated as bad (U1brich et al., 2009). A total of $173 \mathrm{~m} / z$ were included in the

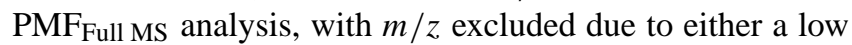
signal (e.g., 19-23), known interferences (e.g., 18), a signal dominated by gaseous species (e.g., 28), high background levels (e.g., 149), or non-linear contributions $(m / z$ 39). While $\mathrm{m} / z 39$ (potassium) could be useful in a PMF analysis of the full mass spectrum for the potential identification of certain factors (e.g., biomass burning), it was excluded due to nonlinearities in the signal. Potassium can ionize by two different ionization pathways, namely electron impact and surface ionization, each bearing a different relative ionization efficiency (RIE) (Drewnick et al., 2006). The amount of signal measured from potassium thus depends not only on the actual initial potassium mass, but also on the particle's history within the AMS. Quantifying the relative degree of vaporization via electron impaction vs. surface ionization is difficult, as this ratio is not entirely stable over time (e.g., minor drifts in tuning, fluctuations in the vaporizer temperature), and may depend on the particle composition. Initial PMF tests indicated that potassium inclusion did not aid in the extraction of a biomass burning organic aerosol factor. Although some potassium is also found at $m / z 41$, this fragment was dominated by organics (potassium contribution $<7 \%$ ). This signal could be removed, although doing so requires referring to the non-linear $m / z 39$. Due to the low contribution of potassium at $m / z$ 41, this fragment was thus left unaltered to avoid introducing additional noise to the matrix.

In addition to the uncertainties as described above, a global uncertainty of $5 \%$ of the data (the $\mathrm{C} 3$ parameter) was added to the uncertainty matrix, in a similar fashion to Brown et al. (2012). Solutions were interpreted based on the resulting factor profiles and temporal trends. The factor profile mass spectra were compared with those extracted from other PMF studies of AMS data; however, it should be noted that these comparisons were interpreted with care due to methodological differences between $\mathrm{PMF}_{\text {Full MS }}$ and $\mathrm{PMF}_{\text {Org MS }}$ analyses. Factor temporal trends were examined for particular behaviors such as diurnal trends and correlations with meteorological conditions and external species (e.g., gases and PM mass).

Two methods were employed to test the robustness of the factor analysis of the AMS data: FPeak rotational analysis and bootstrapping. The effect of global matrix rotations through the FPeak parameter was mainly evaluated in terms of the mass spectra: changes in the mass spectra could be evaluated more objectively than changes in temporal trends, due to the availability of comparison mass spectra from other studies and the lack of a priori knowledge of source temporal trends. However, the effect of FPeak rotations on correlations between some factors and key external measurements was also evaluated. It should be noted that since EPA PMF 4.1 utilizes the multi-linear engine (ME-2), FPeak values are approximately five times greater than those typically used for PMF2 in order to achieve a similar degree of rotation (i.e., in PMF2, FPeaks explored typically range from -2 to 2 ) (Norris et al., 2010). Similar to the approach used by Brown et al. (2012), FPeak rotations were calculated from -10 to 10 in increments of 2 (Brown et al., 2012). This range led to increases in $Q / Q_{\exp }$ of $\sim 1 \%$, indicating that the base solution appeared rotationally robust. Furthermore, this rotational range appeared sufficient to provide an indication of the relative robustness of factors, by comparing the relative degree of rotational ambiguity between factors: the robustness of each factor was examined by applying the AMS fragmentation species extraction algorithm (Allan et al., 2003) to the resulting FPeak factor profiles, and the species mass fractions across FPeak values were examined. In terms of the bootstrap analysis, 100 bootstrap iterations were performed. Bootstrap results were mainly interpreted according to the number of unmapped factors (factors that could not be "mapped" to the base case using a threshold uncentered 
correlation coefficient of 0.6). The results of these tests are described in the Supplement.

\subsection{Aerosol mass spectrometer mass quantification}

The use of $\mathrm{NO}_{3 \text { eq }}$ mass proved to be a useful method for obtaining better mass estimates, as the various relative ionization efficiencies (RIEs) of component species can be considered in the mass quantification of resolved PMF factors. In the case of PMF of organic MS, only a single multiplicative factor of 1.4 is applied to the data set as a whole to account for the RIE of organics (RIE of 1.4). However, another approach is required for mass estimates of multi-component, combined inorganic and organic mass spectra. Firstly, PMF analysis of the full mass spectrum was performed using nitrate equivalent mass $\left(\mathrm{NO}_{3 \text { eq }}\right)$, whereby an instrument signal was converted to mass using a single RIE (in this case, that for nitrate). Following PMF, the factor species composition was determined through application of the fragmentation scheme to factor mass spectra (Allan et al., 2003, 2004), and an effective factor RIE calculated through weighted averages of RIEs according to the factor composition (Chang et al., 2011). Default RIE values were assumed for the main AMS species, and were used to convert the $\mathrm{NO}_{3 \text { eq }}$ factor mass to "real" mass. It should be noted that this method works well when the defining species' chemical nature is well understood, and fragmentation patterns and RIE values are available (i.e., as for $\mathrm{NO}_{3}^{-}, \mathrm{SO}_{4}^{2-}, \mathrm{NH}_{4}^{+}$, chloride, and organics). However, the AMS has been known to detect other species, such as methanesulfonic acid (Zorn et al., 2008; Langley et al., 2010; Chang et al., 2011) and amines (Silva et al., 2008; Docherty et al., 2011; Hildebrandt et al., 2011), for which less information is available. In particular, it has been shown that, depending on their chemical nature, amines may display a wide range of fragmentation patterns and RIE values (i.e., from 1.3 to 10) (Silva et al., 2008). An indication of the chemical nature of the factor species may thus be integral to the factor mass quantification calculation. Further discussion of the implication of these assumptions is provided in Sect. 3.2.

\subsection{Supporting measurements}

Trace gases were measured using a variety of techniques, namely by quadrupole proton-transfer-reaction mass spectrometry (PTR-MS) (Ionicon, Innsbruck, Austria) to measure Volatile Organic Compounds (VOCs), as well as with other gas analyzers to measure $\mathrm{NO}_{\mathrm{x}}, \mathrm{SO}_{2}, \mathrm{O}_{3}$, and $\mathrm{CO}$. Particle number concentration measurements were provided by a condensation particle counter (model 3010, TSI Inc., Shoreview, MN, USA). Black carbon measurements were also available from an aethalometer (Magee Scientific), and measurements derived from absorption at $880 \mathrm{~nm}$ were used. As reliable collocated sub-micron PM mass concentration measurements were unavailable, PM mass comparisons were made to 5 min $\mathrm{PM}_{2.5}$ measurements obtained by a TEOM (TEOM model 1400ab, Rupprecht and Patashnick, East Greenbush, NY, USA) on board CRUISER. Hourly meteorological measurements were supplied courtesy of Environment Canada, from a meteorological station located $10 \mathrm{~km}$ to the east of MicMac Park in an open field at Windsor Airport $\left(42^{\circ} 16^{\prime} 48^{\prime \prime} \mathrm{N}, 82^{\circ} 57^{\prime} 36^{\prime \prime} \mathrm{W}\right)$. Measurements of wind direction and speed, RH, and visibility were used in this analysis.

\subsection{Assessment of geographic origins}

The geographic origins of the AMS PMF factors were assessed using the conditional probability function (CPF) and the potential source contribution function (PSCF), which have been described elsewhere (Ashbaugh et al., 1985; McGuire et al., 2011). In this study, the CPF threshold was set to the top 25th percentile, and probabilities associated with infrequently observed wind directions (winds $<5 \%$ of the time) were downweighted by 3 . For the PSCF analysis, each cell was chosen to be $0.5^{\circ}$ in both latitude and longitude, and the threshold for the PSCF was set to the top 50th percentile. For the purposes of the Sulfate-OA factor PSCF analysis, three short events known to be associated with local sources were removed from the analysis (see Sect. 3.1.2 for further description). The result is a probability distribution map where higher probabilities indicate more probable regional source regions.

\section{Results and discussion}

An overview of the meteorological conditions observed during the campaign is presented in Fig. 2. Unusually warm January temperatures for southwestern Ontario were observed at the beginning of the campaign. Higher wind speeds were associated with southerly air flow. Wind speeds dropped dramatically towards the end of the campaign, resulting in a stagnation period that resulted in a significant increase in PM mass concentration. The time series of the AMS nonrefractory species, as calculated from the AMS data analysis package, is shown in Fig. 3, and descriptive statistics for these species are listed in Table 1 . On average, prior to PMF analysis, organic aerosol (37\%) and $\mathrm{NO}_{3}^{-}(31 \%)$ were found to contribute most to the non-refractory sub-micron PM mass. The following sections first outline results from PMF analysis of the full mass spectrum, followed by PMF analysis of the organics. Finally, results from both analyses are compared.

\subsection{PMF of AMS full mass spectra}

$\mathrm{PMF}_{\text {Full MS }}$ analysis showed that six factors best captured the variability in the data. The following factors were retrieved: Amine; Sulfate-OA, containing mostly ammonium sulfate; Nitrate-OA, containing mostly ammonium nitrate; Chloride, composed mostly of ammonium chloride; HOA, a 


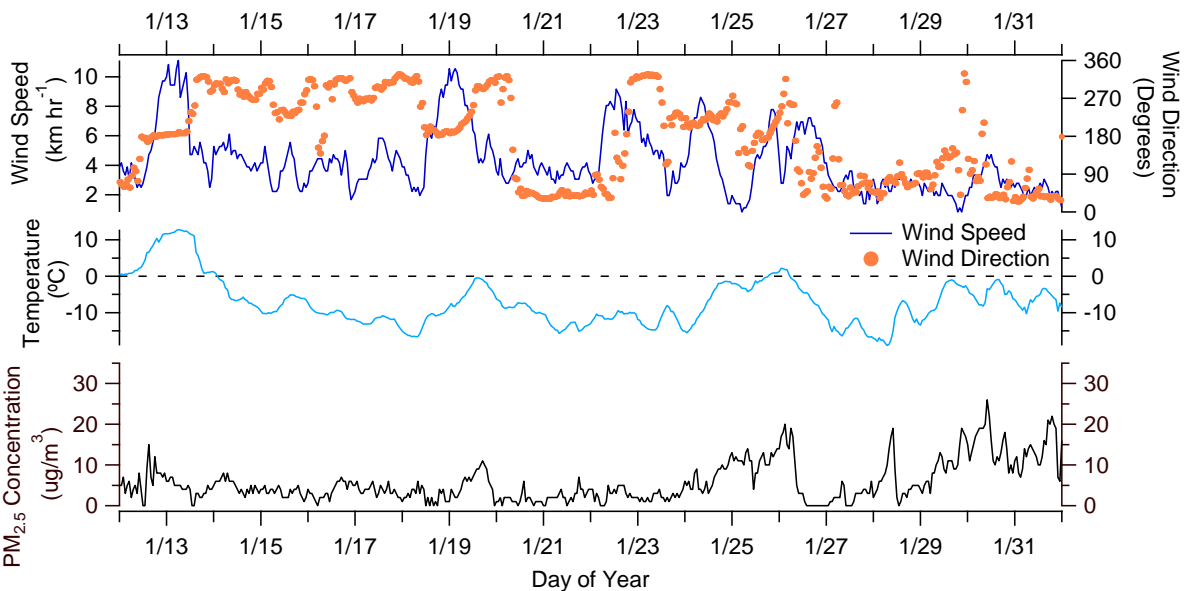

Figure 2. Meteorological conditions and $\mathrm{PM}_{2.5}$ mass concentration from the CRUISER TEOM for the MicMac Park winter campaign.

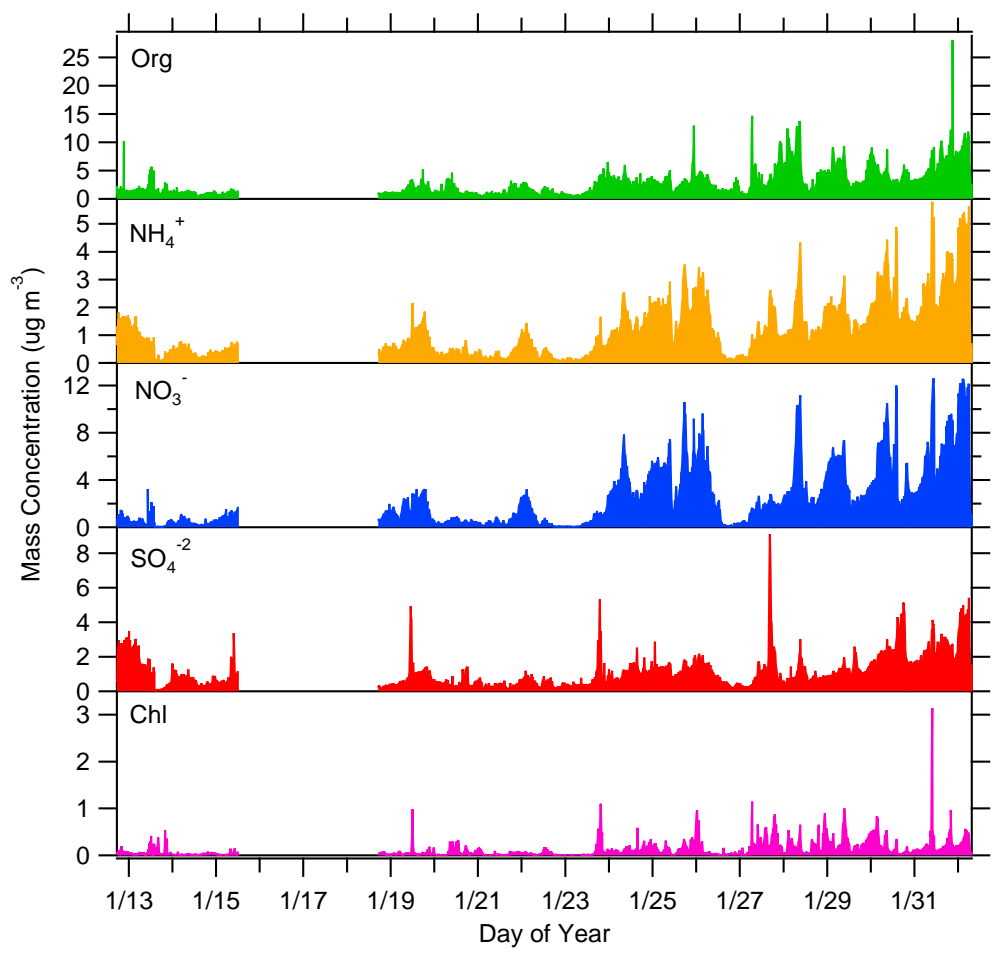

Figure 3. Time series of AMS-measured non-refractory sub-micron PM species.

hydrocarbon-like organic factor, which represented primary organic aerosol; and OOA, an oxygenated organic aerosol factor. Figures 4 and 5 show the time series (in local time) and factor profiles, respectively. Figure 6 shows the mass spectra of each factor's organic components, and Fig. 7 details each factor's chemical composition by species and factor component.

Solutions containing two through ten factors were analyzed. In brief, as with the six-factor solution, the five-, seven-, and eight-factor solutions contained almost the same five factors (Sulfate-OA, Nitrate-OA, Chloride, HOA, and
Amine). While the five-factor solution did not extract an OOA factor, the seven-factor solution split the OOA resolved from the six-factor solution into a similar OOA factor, as well as another OA factor that did not sufficiently resemble any known mass spectra. The eight-factor solution added a local sulfate factor. More detailed solution descriptions and a justification of the six- to eight-factor solutions are presented in the Supplement. The six-factor solution was chosen for the following reasons: among 100 random runs, all runs converged and displayed a constant, global minimum $Q$ value; higher-order solutions did not explain significantly 


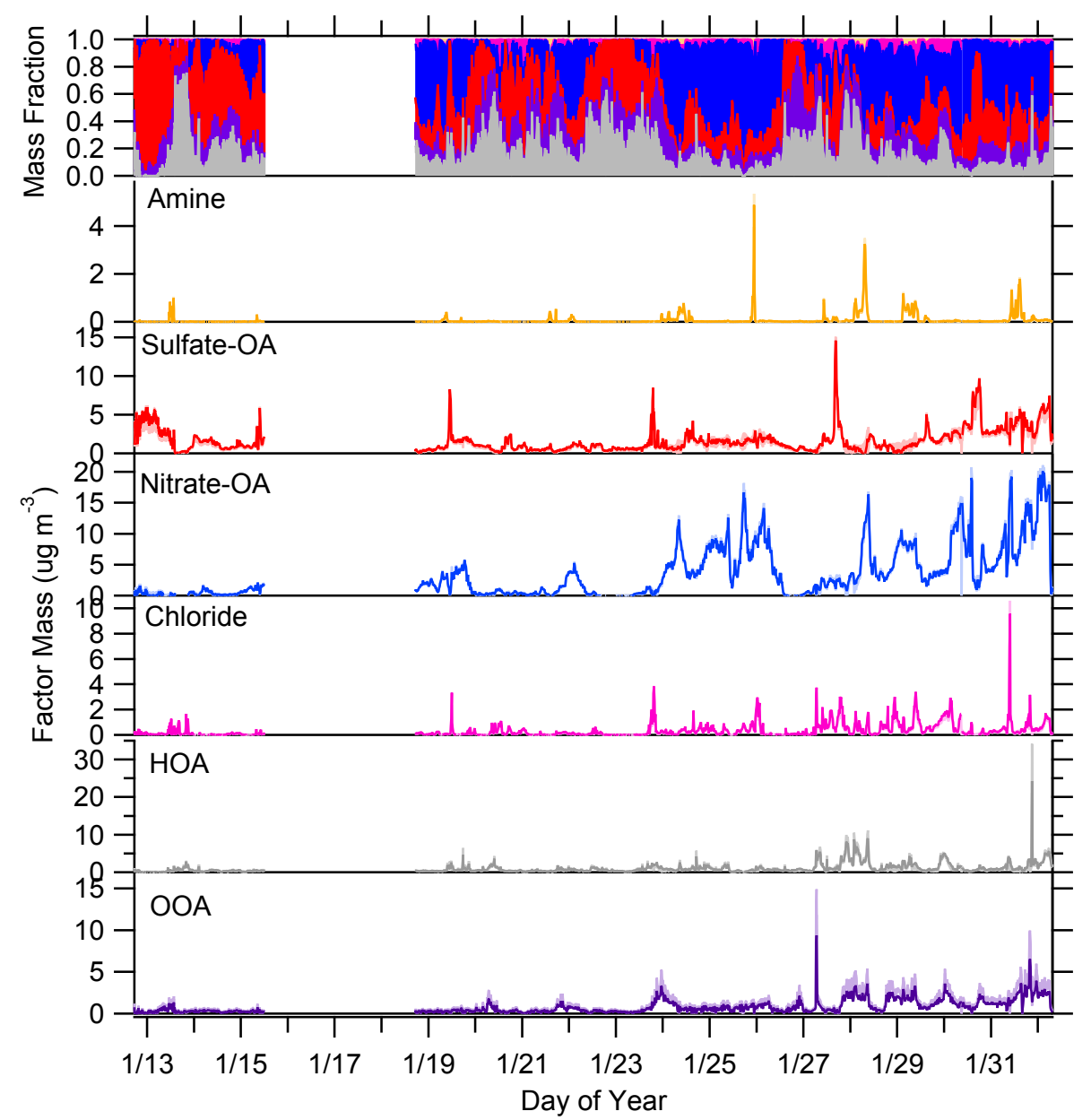

Figure 4. Time series of the factors from the six-factor solution from PMF Full MS analysis. The solid line represents FPeak $=0$, and the range of uncertainties through FPeak analysis $(-10$ and +10$)$ is shown in the shaded regions.

more variance in the data; and factors from this solution were the most physically meaningful. The following sections detail findings for each factor, with a focus on new insights into aerosol sources and processes due to the incorporation of both the organic and inorganic aerosol fractions into the PMF analysis.

\subsubsection{Amine factor}

The Amine factor's time series, shown in Fig. 4, was characterized by several short-duration events. The Amine factor MS (Fig. 5) was distinctly different from the other factors due to the presence of fragments such as $m / z 30,58,86$, and 100 . This factor also contained a significant signal at $m / z 30$, with the $m / z 30 / 46$ ratio much higher than that for nitrate, suggesting the presence of other ions (e.g., $\mathrm{CH}_{4} \mathrm{~N}^{+}$). The organic functionality of this factor was examined through the delta $(\Delta)$ pattern displayed by its mass spectral profile, whereby $\Delta=m / z-14 n+1$ (where $n$ is the number of $\mathrm{CH}_{2}$ groups left in the functional group) (McLafferty and Tureček, 1993). Given its characteristic fragments and strong
$\Delta=3$ pattern (i.e., $30,44,58,72,86,100$, etc.) representative of alkyl amines $\left(\mathrm{C}_{n} \mathrm{H}_{2 n+2} \mathrm{~N}\right)$, this factor was assigned as Amine. The Amine factor was robust in the solution, emerging in each solution involving at least three factors. In terms of assessing rotational ambiguity from FPeak analysis, the Amine factor appeared robust, and rotationally fixed (Fig. 5).

Gas- and particle-phase amines have been recorded in the troposphere for some time, and can be emitted from a variety of sources. The largest global sources of amines are animal husbandry, industrial operations, and wastewater treatment (Ge et al., 2011). Gaseous aliphatic amines at high concentrations can have serious consequences for human health, with effects ranging from irritation of mucosal membranes, to blood clots, and potentially cancer (Greim et al., 1998). Particle-phase amines have been measured in widely different settings, ranging from rural areas in Utah (Silva et al., 2008) and Ontario (McGuire et al., 2011; Rehbein et al., 2011), to heavily urbanized areas such as Mexico City (Aiken et al., 2009), Riverside, California (Pratt et al., 2009), and Toronto (Tan et al., 2002; Rehbein et al., 2011). In this 
Table 1. Descriptive statistics for AMS-measured non-refractory sub-micron PM species, pre- and post-PMF analysis $\left(\mu \mathrm{g} \mathrm{m}^{-3}\right.$ ).

\begin{tabular}{|c|c|c|c|c|c|c|c|c|c|c|c|c|}
\hline & \multicolumn{2}{|c|}{ Org } & \multicolumn{2}{|c|}{$\mathrm{NH}_{4}^{+}$} & \multicolumn{2}{|c|}{$\mathrm{NO}_{3}^{-}$} & \multicolumn{2}{|c|}{$\mathrm{SO}_{4}^{2-}$} & \multicolumn{2}{|c|}{$\mathrm{Cl}^{-}$} & \multicolumn{2}{|c|}{ Total } \\
\hline & Pre & Post & Pre & Post & Pre & Post & Pre & Post & Pre & Post & Pre & Post \\
\hline Mean & 2.73 & 2.45 & 1.13 & 1.15 & 2.28 & 2.20 & 1.18 & 1.13 & 0.12 & 0.12 & 7.45 & 7.10 \\
\hline $1 \sigma$ & 2.41 & 2.17 & 1.01 & 1.04 & 2.58 & 2.53 & 0.97 & 0.91 & 0.18 & 0.17 & 6.30 & 6.12 \\
\hline Min & 0.29 & 0.00 & 0.00 & 0.00 & 0.01 & 0.00 & 0.03 & 0.00 & 0.00 & 0.00 & 0.58 & 0.00 \\
\hline Max & 28.08 & 24.61 & 5.80 & 6.22 & 12.61 & 12.56 & 9.09 & 7.24 & 3.14 & 2.79 & 43.79 & 41.15 \\
\hline
\end{tabular}

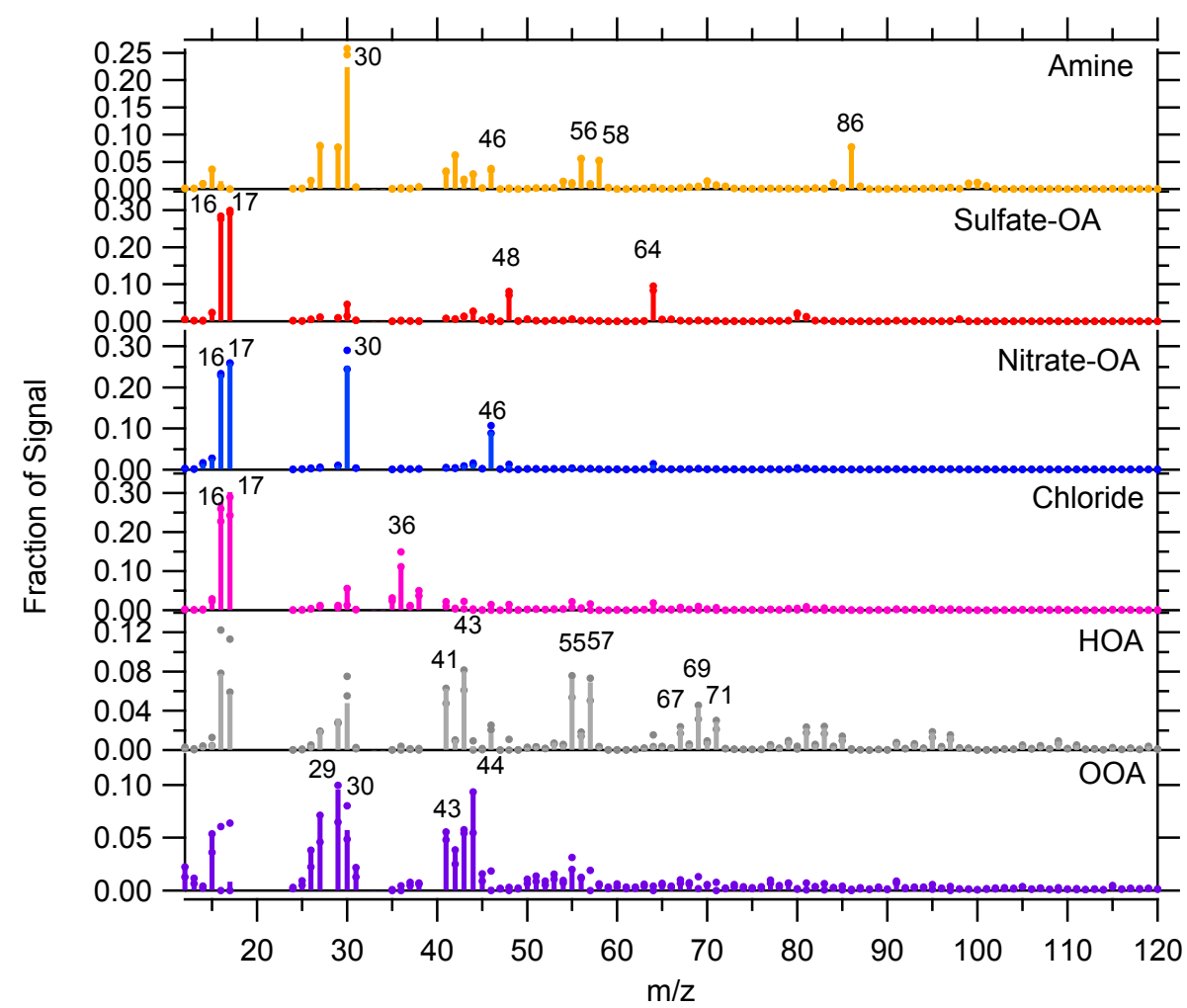

Figure 5. Mass spectra of factors from the six-factor solution from $\mathrm{PMF}_{\mathrm{Full}} \mathrm{MS}$ analysis. Bars represent the central, chosen rotation, and dots show the range in mass spectral variation from FPeak rotations $(-10$ and 10$)$.

study, the measurement site was located in an urban industrial setting, with known amine sources located nearby: a wastewater reclamation plant and a major amine chemical manufacturer were located 1 and $13 \mathrm{~km}$ to the southwest, respectively. According to the TRI and NPRI inventories, the amine manufacturer was the largest monitored emitter of TEA in 2005 in the Windsor-Detroit region (Environment Canada, 2013; US EPA, 2013b). The strong southwest directionality observed in the CPF (Fig. 8a) indicated that both of these sources may have contributed. The sharp bursts in temporality were consistent with local sources such as fugitive emissions from industrial operations.

In order to quantify the Amine factor's mass concentration, it was necessary to obtain an estimate of the factor's effective RIE. Unfortunately, an effective RIE could not be determined through application of the traditional AMS fragmentation table, as the factor contained amines that were not represented in the table. It is possible to alter the fragmentation table to include additional species, provided the nature of the measured species is known and a species fragmentation pattern is available. This has previously been accomplished, for instance, with methanesulfonic acid (MSA) (Zorn et al., 2008; Langley et al., 2010; Chang et al., 2011). In a study by Chang et al. (2011), MSA could be positively identified due to unique marker fragments and a lack of interfering species, and its mass could be calculated through application of a laboratory-determined fragmentation pattern and RIE (Chang et al., 2011). Taking this approach was not obvious for the present study, as the particular amine compound(s) could not be identified easily, and there was a possibility that 


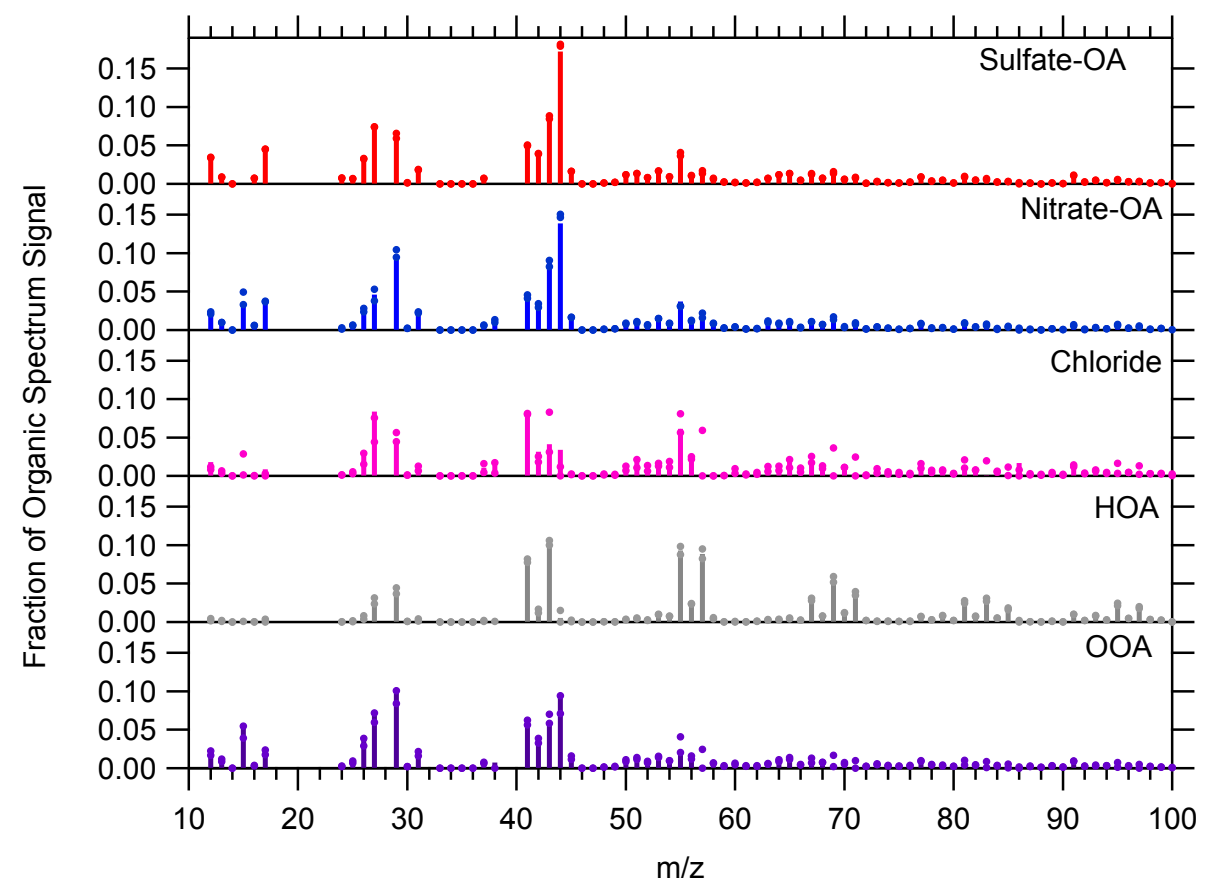

Figure 6. Mass spectra of the organic fraction of the factors from the six-factor solution from PMF Full MS analysis. The Amine factor is not shown due to insufficient information regarding the chemical nature of the Amine factor. Bars represent the central, chosen rotation, and dots show the range in mass spectral variation from FPeak rotations $(-10$ and 10$)$.

the factor represented a linear combination of different amine species with different RIEs and fragmentation patterns.

Nonetheless, the nature of the Amine factor was investigated to determine a potential factor RIE for mass estimation. Amines have been shown to exhibit a wide range of RIEs, depending on their chemical nature. AMS measurements of amines present in salt form, such as methylammonium chloride, dimethylammonium chloride, and trimethylammonium chloride, have shown that the amine fraction in these compounds can display RIEs from 5 to 10 (Silva et al., 2008). However, oxidized alkyl amines such as trimethylamine- $n$ oxide (TMAO) have been shown to ionize with an RIE of 1.3, a value closer to organics $(\mathrm{RIE}=1.4)$ (Silva et al., 2008). It has been hypothesized that aminium salts exhibit a relatively high RIE due to surface ionization on the AMS vaporizer, similar to that observed for potassium salts (Silva et al., 2008). Depending on the type of amine compound or mixture of compounds the Amine factor represents, its RIE may thus lie within a wide range (i.e., 1.3-10).

A reasonable estimate of an effective RIE for the Amine factor was sought by examining the data for a dominant particle phase amine formation pathway, namely for signs of aqueous dissolution, acid-base reaction, or oxidation $(\mathrm{Ge}$ et al., 2011). First, the amine factor time series was examined relative to external measurements. Dissolution into water droplets was investigated by comparing the time series with periods of rain, fog, or high RH: no association could be identified, as the Amine factor often appeared on clear days with lower RH. Reaction with acidic species was also considered through time series analysis of the extent of neutralization, a useful metric for determining periods of particle acidity. However, this metric cannot provide reliable information, as $\mathrm{NO}_{3}^{-}$cannot be quantified properly prior to PMF analysis, due to amine interferences. The temporality of the Amine factor was also investigated because the daytime maximum identified for a similar factor identified by Sun et al. (2012) suggested that photo-oxidation and condensation can also be a likely formation pathway (Sun et al., 2012). However, no consistent diurnal trend was noted. Docherty et al. (2011) reported similar difficulty in determining the origins of an amine-related factor through time series analysis of results from a PMF $\mathrm{Org}_{\mathrm{MS}}$ analysis (Docherty et al., 2011).

Mass spectral comparison to laboratory-generated amine MS provided a better indication of the chemical nature of the Amine factor. Among comparisons with mass spectra from suspected amine compounds reported in the NIST library, the Amine factor's profile was most similar to that of triethylamine (TEA: $\mathrm{C}_{6} \mathrm{H}_{15} \mathrm{~N}, 101 \mathrm{~g} \mathrm{~mol}^{-1}$ ), as demonstrated in Fig. S2.1 in the Supplement $\left(r^{2}=0.23\right)$ (Stein, 2013). However, direct comparisons between AMS and NIST mass spectra are interpreted with caution, as they use different ionization techniques that can lead to mass spectral differences (Canagaratna et al., 2007a). Nonetheless, the amine spectra showed the same characteristic peaks (i.e., $m / z 56,58$, and 86). 


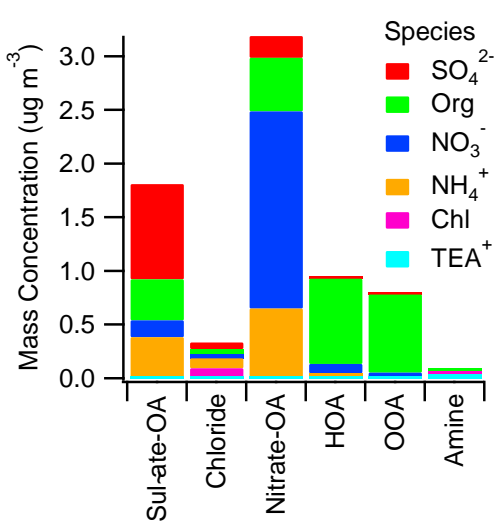

(a)

(c)

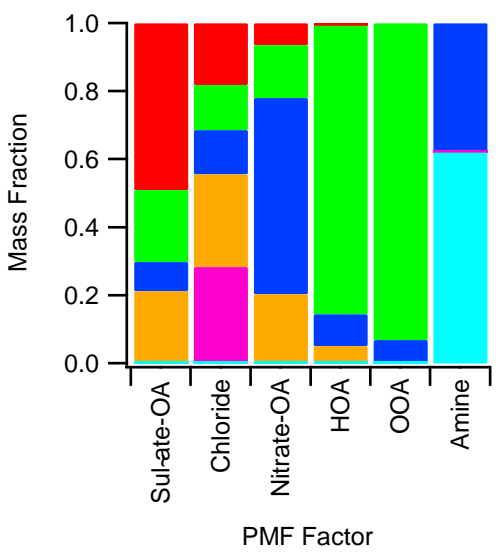

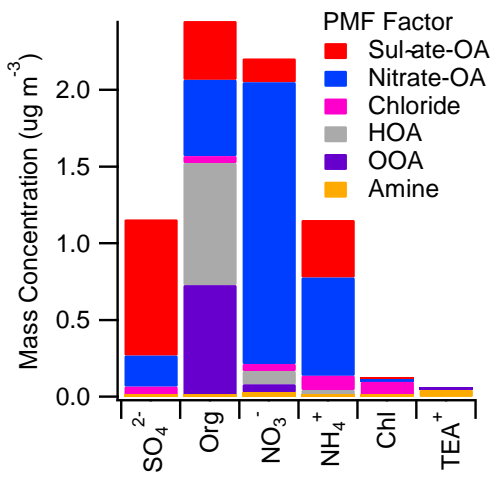

(b)

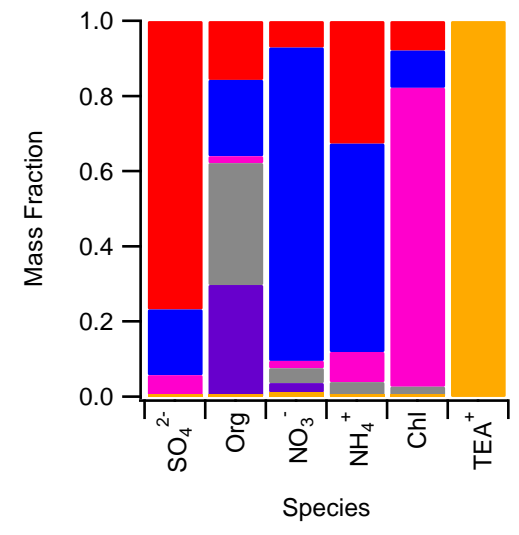

(d)

Figure 7. Chemical composition by factor and species components of the six PMF factors from the PMF Full MS analysis.

Examination of AMS mass spectra of amines provided further perspective. Amines have been studied by AMS in chamber experiments to examine potential reaction pathways, for example oxidation, such as by nitrate radicals (Murphy et al., 2007; Silva et al., 2008; Malloy et al., 2009) and reaction with acid gases such as $\mathrm{HNO}_{3}$ (Murphy et al., 2007; Silva et al., 2008). These different mechanisms can actually lead to similar mass spectra (Malloy et al., 2009). The MS of the Amine factor in this study was determined to be very similar to that of TEAN reported by Murphy et al. (2007), resultant from reaction between TEA and $\mathrm{HNO}_{3}$, with signals at $m / z 30,46,58,86$ and 100 (Murphy et al., 2007). One sign of reaction formation of amine salts from reaction with $\mathrm{HNO}_{3}$, as reported by Malloy et al., is the presence of significant signals from $\mathrm{NO}^{+}$and $\mathrm{NO}_{2}^{+}$(at $m / z 30$ and 46) (Malloy et al., 2009). Examination of the MS from the Amine factor showed that the signal was very high at $m / z 30$, and some signal was also present at $m / z 46$, although as mentioned previously, $m / z 30$ can also represent $\mathrm{CH}_{4} \mathrm{~N}^{+}$ and $\mathrm{CH}_{2} \mathrm{O}^{+}$. There were no mass spectral signs to suggest an oxidation mechanism over salt formation. Ultimately, the factor was interpreted as being dominated by TEAN.

With this interpretation, an effective RIE for the factor was calculated. This was achieved by assuming a neutralized factor, and that TEAN was the only component. Though there did appear to be other contributions (e.g., $\mathrm{SO}_{4}^{2-}$ ), these appeared to be very low. The nitrate fraction was calculated using the nitrate fragmentation pattern, with $\mathrm{m} / z 30$ altered to reflect the isotopic ratio between $\mathrm{m} / \mathrm{z} 30$ and 46 obtained from calibration. The RIE of the amine fraction was determined by assuming factor neutrality, and that the remaining mass following subtraction of nitrate was triethylammonium. An RIE for the amine fraction of 6.0 was determined from this calculation, which fell within the range of RIEs previously measured for various amine salts. With the nitrate fraction taken into consideration, an effective RIE of 4.3 was established. This amine salt interpretation appeared to provide reasonable mass concentrations, as the calculated RIE resulted in spikes $(<2 \mathrm{~h})$ reaching a magnitude of $4.8 \mu \mathrm{g} \mathrm{m}^{-3}$, while an RIE of 1.3, reflective of oxidized amines, resulted in concentrations exceeding $15 \mu \mathrm{g} \mathrm{m}^{-3}$. While the factor was assumed to be dominated by TEAN, its exact nature could not be validated; no amine fragmentation pattern proved an exact match, and external high time-resolution collocated sub-micron PM mass measurements were not available to validate the RIE through PM mass comparison. In considering acid-base chemistry, calculations by Murphy et al. (2007) have shown that the formation of aminium salts 

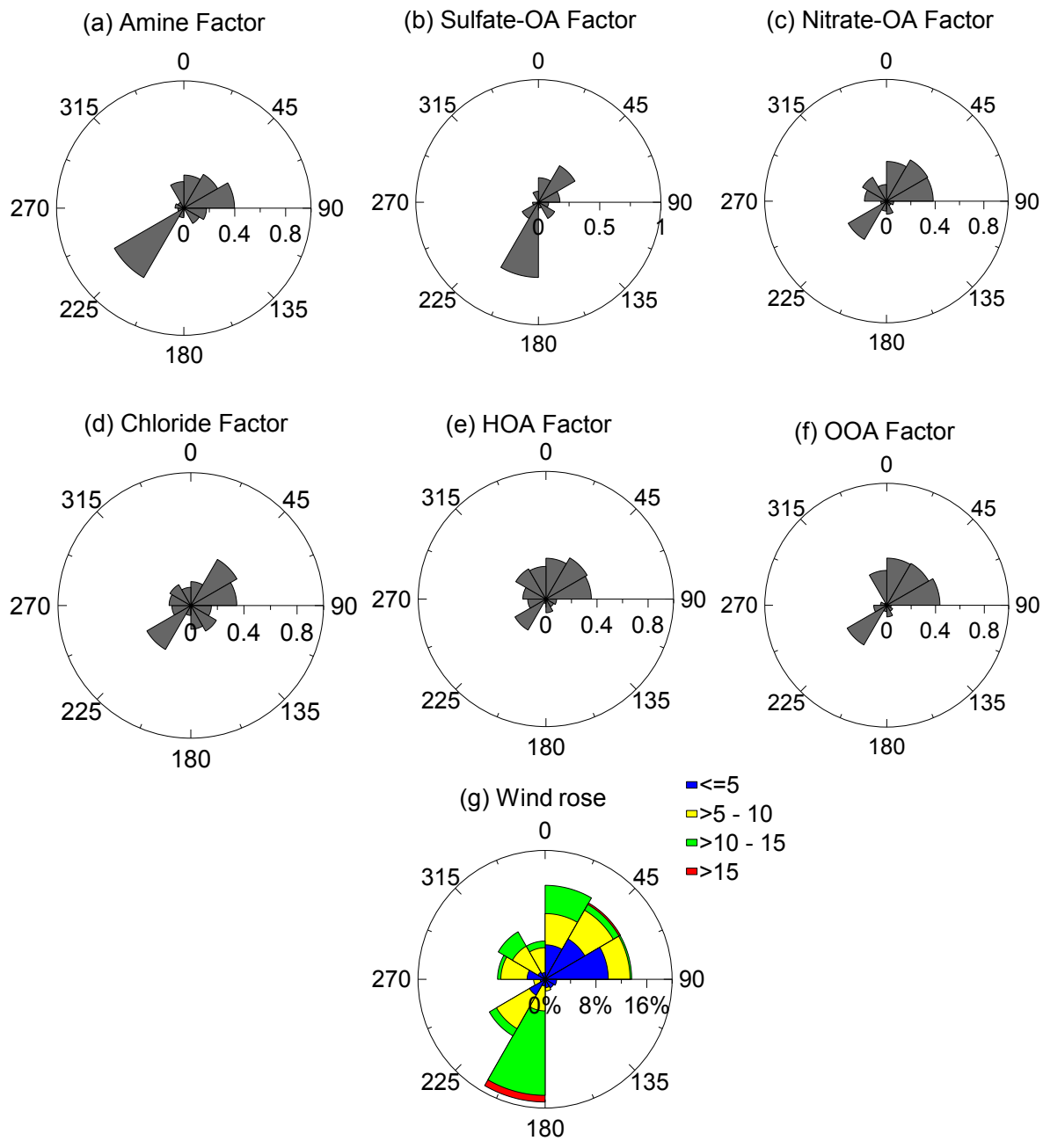

Figure 8. Conditional probability function $(\mathrm{CPF})$ plots for the six factors from the six-factor solution of the PMF $\mathrm{Full}_{\mathrm{MS}}$ analysis, along with a wind rose plot (wind speed in $\mathrm{ms}^{-1}$ ). The strongest wind dependence is observed for the Amine and Sulfate-OA factors, which show strong, yet slightly different directional associations to the southwest.

from the reaction of $\mathrm{HNO}_{3}$ and TEA is only thermodynamically favorable in the presence of very low $\mathrm{NH}_{3}$ (Murphy et al., 2007). These conditions may have been provided by plumes from a nearby source.

Four studies to date have identified an amine-related factor through PMF of AMS mass spectra to the authors' knowledge (Aiken et al., 2009; Docherty et al., 2011; Hildebrandt et al., 2011; Sun et al., 2012). The analyses by Aiken et al., Docherty et al. (2011) and Hildebrandt et al. (2011) all extracted the amine factors from PMF of the organic MS, while Sun et al. (2012) extracted it from the full MS. Since the former three applied PMF only to the organic MS, significant mass that may have been associated with this factor (i.e., $m / z 30$ ) was potentially not captured. Furthermore, the latter study did not take into account the potential for a wide range of RIEs for the amine-related species, as highlighted by Silva et al. (2008) and discussed in this study. Regardless of the exact methodology, it can be seen that PMF can be effective in resolving atypical factors such as amines.

\subsubsection{Sulfate-OA factor}

The time series and mass spectral profile of the SulfateOA factor are shown in Figs. 4 and 5, respectively, and the chemical composition breakdown for this factor is shown in Fig. 7. A mass spectral comparison between the SulfateOA factor and the published MS of atomized $\left(\mathrm{NH}_{4}\right)_{2} \mathrm{SO}_{4}$ (Hogrefe et al., 2004) shows that they exhibit the same major peaks at $m / z 16,17,48,64,80$, and 81 , and compare well with an $r^{2}$ of 0.74 . The Sulfate-OA factor on average contributed $1.81 \mu \mathrm{g} \mathrm{m}^{-3}$, or $25 \%$, to the sub-micron PM mass, and showed the highest mass concentrations towards the beginning of the campaign, when air masses originated from the south. Overall, this factor showed a slight correlation with $\mathrm{PM}_{2.5}$ mass concentration $\left(r^{2}=0.21\right)$. A 
Table 2. Chemical composition of the six factors from the PMF Full MS analysis, extent of neutralization, and F44 for each factor's organic fraction.

\begin{tabular}{|c|c|c|c|c|c|c|c|c|c|}
\hline \multirow[t]{2}{*}{ PMF factor } & \multicolumn{2}{|c|}{$\begin{array}{l}\text { Sub-micron } \\
\text { PM mass }\end{array}$} & \multicolumn{5}{|c|}{$\begin{array}{l}\text { AMS species (factor mass fractional } \\
\text { contribution) }\end{array}$} & \multirow[t]{2}{*}{ NeutExt } & \multirow[t]{2}{*}{ F44 } \\
\hline & $\left(\mu \mathrm{g} \mathrm{m}^{-3}\right)$ & $(\%)$ & $\mathrm{SO}_{4}^{2-}$ & Org & $\mathrm{NO}_{3}^{-}$ & $\mathrm{NH}_{4}^{+}$ & $\mathrm{Cl}^{-}$ & & \\
\hline Sulfate-OA & 1.81 & 25 & 0.49 & 0.21 & 0.09 & 0.21 & 0.01 & 0.99 & 0.15 \\
\hline Nitrate-OA & 3.19 & 45 & 0.06 & 0.16 & 0.58 & 0.20 & 0.00 & 1.04 & 0.12 \\
\hline Chloride & 0.34 & 5 & 0.18 & 0.13 & 0.13 & 0.27 & 0.28 & 1.09 & 0.03 \\
\hline $\mathrm{HOA}$ & 0.94 & 13 & 0.01 & 0.85 & 0.09 & 0.05 & 0.00 & 1.62 & 0.01 \\
\hline OOA & 0.78 & 11 & 0.00 & 0.93 & 0.07 & 0.00 & 0.00 & - & 0.09 \\
\hline Amine & 0.07 & 1 & - & - & 0.38 & - & - & - & - \\
\hline
\end{tabular}

moderate correlation with $\mathrm{SO}_{2}\left(r^{2}=0.31\right)$ implied that this factor was likely not only influenced by long-range transport, but also by local sources. A more local influence was determined through examination of these temporal trends, which showed that several spikes in the Sulfate-OA factor coincided with large spikes (up to $58 \mathrm{ppb}$ ) of $\mathrm{SO}_{2}$. Local (within the metropolitan area) and local-to-regional (within $\sim 100 \mathrm{~km}$ ) geographic origins for the Sulfate-OA factor were investigated by CPF. This highlighted a strong association with emissions from the southwest (Fig. 8b), which was consistent with some local and local-to-regional coal-fired power plants (Fig. 1). Three large $\mathrm{SO}_{4}^{2-}$ spikes were observed on 19, 24, and 27 January: the first two were associated with the westsouthwest, and the last with the southeast, and all of them were likely associated with local coal-fired power plants. A smaller, yet still significant influence from the northeast was also observed, which may have been associated with emissions from coal plants located to the northeast. The aforementioned spikes were all associated with large excursions in $\mathrm{SO}_{2}(24,34$, and $58 \mathrm{ppb}$, respectively), and each lasted about 2-6h. While the CPF on the whole demonstrated strong directionality to the southwest, this method cannot resolve how far away the responsible source(s) are actually located. Since southwesterly winds in Windsor are also consistent with typical synoptic flows for this region, even in winter, and there are known large $\mathrm{SO}_{2}$ emissions sources located farther away in the Ohio River valley, regional influences for the Sulfate-OA factor were also investigated using the PSCF (Fig. 9a). The PSCF calculations for all factors were performed using data greater than the 50th percentile, but for the Sulfate-OA factor, the three spikes associated with more local emissions were removed. The PSCF highlighted highprobability source regions around the Ohio River valley, an area known as a major $\mathrm{SO}_{2}$ source due to the presence of many large coal-fired power plants. A dominant regional influence was also demonstrated by a reasonably constant diurnal profile (Fig. 11a). The geographic origins of the factor were also consistent with those of a sulfate factor derived from a long-term receptor modeling study of Windsor (Jeong

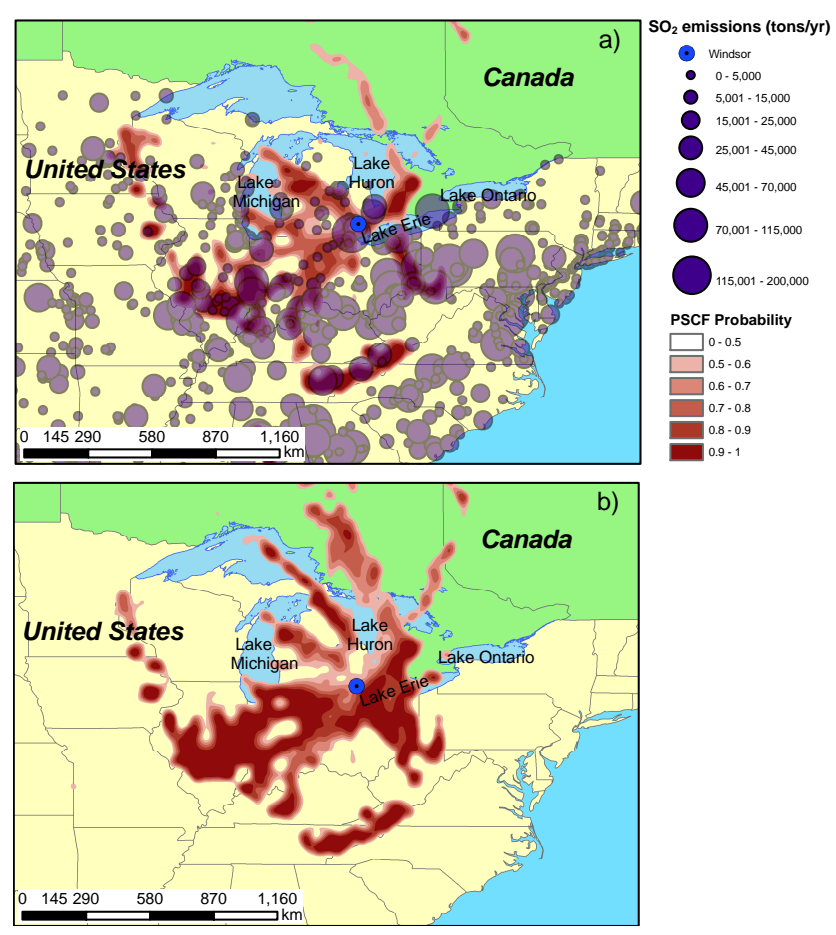

Figure 9. Potential source contribution function (PSCF) plot for the Sulfate-OA (a) and Nitrate-OA (b) factors from the PMF Full MS analysis. Both factors showed regional source influences, with the Sulfate-OA factor showing more prominent, distant influences to the south and southwest. The Nitrate-OA factor showed the most prominent influences to the southwest, over Indiana and Illinois.

et al., 2011), and the nearby rural location of Harrow, Ontario (McGuire et al., 2011).

As the $\mathrm{NH}_{4}^{+}$and $\mathrm{SO}_{4}^{2-}$ contained within the Sulfate-OA factor likely formed an $\left(\mathrm{NH}_{4}\right)_{2} \mathrm{SO}_{4}$ salt, the extent of neutralization was calculated (Table 2). It was assumed that the only species capable of participating in the neutralization reaction, in this factor and in others, were $\mathrm{NH}_{4}^{+}, \mathrm{NO}_{3}^{-}, \mathrm{SO}_{4}^{2-}$, and $\mathrm{Cl}^{-}$. Aminium species were assumed to have been effectively separated into the Amine factor through PMF, and thus it was assumed that they did not contribute to the neutralization of 
other factors. The extent of neutralization $\left(\right.$ Neut $\left._{\text {Ext }}\right)$, reported as the ratio of cations/anions in units of molar equivalents, was defined by

Neut $_{\text {Ext }}=\left(\frac{\frac{\mathrm{NH}_{4}^{+}}{18}}{\frac{2 \mathrm{SO}_{4}^{2-}}{96}+\frac{\mathrm{NO}_{3}^{-}}{62}+\frac{\mathrm{Chl}}{35.5}}\right)$,

where a neutral factor shows a Neut ${ }_{\text {Ext }}$ of 1 , and acidic factors show values less than 1 .

The extent of neutralization of the Sulfate-OA factor was 0.99 , indicating that the factor was reasonably neutral. It should be noted that a source of uncertainty in this value lies in the use of default RIE values for most species. Despite this potential uncertainty, the factor appeared neutral, similar to several other factors. Rotational analysis showed that the composition of this factor, and thus the degree of neutralization, did not change with FPeak rotations (Fig. S2.5 in the Supplement). This suggested that regional rather than local sources of $\mathrm{SO}_{4}^{2-}$ had a greater influence on the chemical composition of this factor. While the Sulfate-OA factor appeared neutralized, simultaneous $\mathrm{SO}_{2}$ and $\mathrm{SO}_{4}^{2-}$ spikes suggested contributions from more local, possibly primary $\mathrm{SO}_{4}^{2-}$ emissions sources, which may have been more acidic. As highlighted in Fig. 10a, these $\mathrm{SO}_{4}^{2-}$ events, while high in mass, did not account for a significant fraction of the total sulfur, due to the magnitude of the coincident $\mathrm{SO}_{2}$ spikes (up to $65 \mathrm{ppb}, 1 \mathrm{~min}$ average). This could be attributed to the observed winter conditions that do not favor rapid oxidation of $\mathrm{SO}_{2}$. Interestingly, a smaller $\mathrm{SO}_{4}^{2-}$ size distribution was observed during these spikes (from AMS p-ToF data), substantiating local $\mathrm{SO}_{4}^{2-}$ contributions. Figure $10 \mathrm{~b}$ shows that $\mathrm{SO}_{4}^{2-}$ measured over the entire campaign showed an average modal size of $500 \mathrm{~nm}$ (accumulation mode consistent with regional transport), while the size modes observed during the spikes were much smaller $(150-250 \mathrm{~nm})$. These results indicate that proximate sources of $\mathrm{SO}_{4}^{2-}$ contributed to the total $\mathrm{SO}_{4}^{2-}$, particularly during the largest $\mathrm{SO}_{4}^{2-}$ spikes.

Examination of the residuals from the six-factor solution shows that some AMS signal cannot be accounted for during the Sulfate-OA factor/SO ${ }_{4}^{2-}$ spikes, indicating that another factor may be required to explain more fully the mass during these spikes. As a result, higher-order solutions were investigated, and are reported in the Supplement. Figure S2.12 in the Supplement shows that at eight factors, the SulfateOA factor split into two factors: a regional sulfate factor that was characterized by synoptic-scale temporal rises, and a local sulfate factor that captured the $\mathrm{SO}_{4}^{2-}$ spikes. While the local sulfate factor appeared meaningful in that it captured residual $\mathrm{SO}_{4}^{2-}$, the eight-factor solution could not be justified for several reasons, which are further detailed in the Supplement. First, while the local sulfate factor appeared acidic $\left(\right.$ Neut $\left._{\text {Ext }}=0.25\right)$, consistent with more local origins, the regional sulfate factor in the eight-factor solution now appeared over-neutralized $\left(\mathrm{Neut}_{\mathrm{Ext}}=1.27\right)$ relative to a reasonably
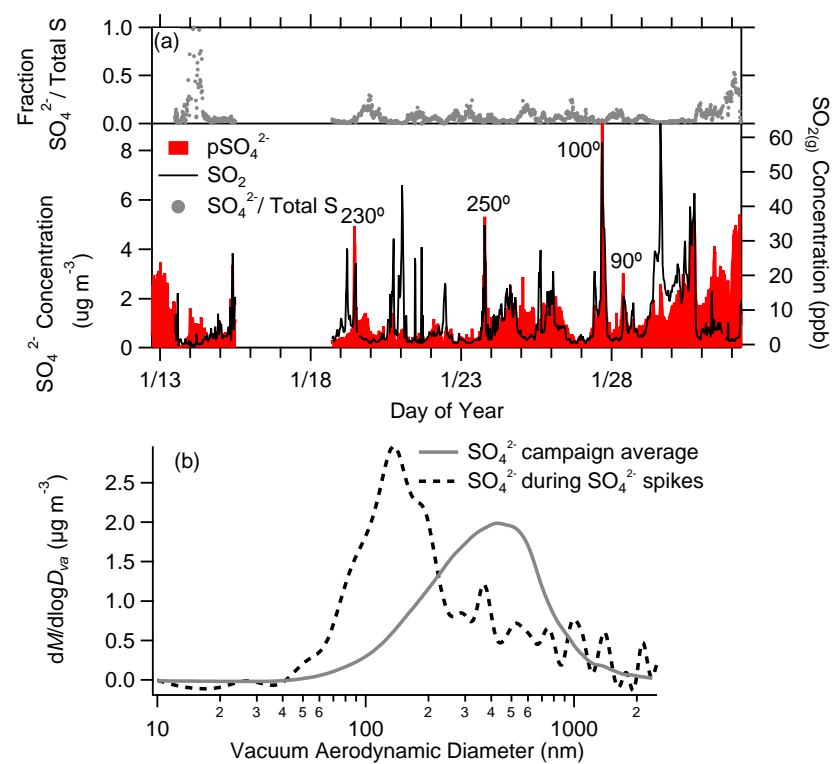

Figure 10. Particulate sulfate concentration $\left(\mathrm{SO}_{4}^{2-}\right)$ vs. $\mathrm{SO}_{2(g)}$ concentration, and fraction of $\mathrm{SO}_{4}^{2-}$ /Total $S$ (Total $S=\mathrm{SO}_{4}^{2-}+\mathrm{SO}_{2}$ ) (a). Due to the winter conditions, the fractional contribution of $\mathrm{pSO}_{4}^{2-}$ to total $S$ was typically very low. Shown in (b) are the averaged particle size distributions of $\mathrm{AMS} \mathrm{SO}_{4}^{2-}$ over the entire campaign, as well as during the extreme $\mathrm{SO}_{4}^{2-}$ spikes. Particulate $\mathrm{SO}_{4}^{2-}$ measured during the spikes appeared highly local due to their significantly smaller modal diameters.

unchanged and neutral Nitrate-OA factor. Second, the OOA factor appeared split, resulting in an OA factor that did not show a strong enough resemblance to any known, ambient deconvolved OA. Finally, the correlation between HOA factor MS from the eight-factor solution and the reference HOA was worse than in lower-order solutions. Mass spectral examination showed that more signal was apportioned to $m / z 16$ and 17 in higher-order solutions; this effect was mainly attributed to solution uncertainty, as FPeak analysis of the sixfactor solution showed some variability in these fragments upon rotation. Although the Sulfate-OA factor from the sixfactor solution did not capture fully the variability and types of $\mathrm{SO}_{4}^{2-}$ observed, it appeared stable, with a low degree of rotational uncertainty (Fig. S2.5 in the Supplement). It is possible that the local sulfate factor could be extracted more definitively if it were more prominent in the data set. However, resolving acidic factors may not always be realistic, as data quality, receptor site complexity and atmospheric dynamics can all influence factor resolution. Nonetheless, resolving acidic factors could be useful from a parameterization perspective for resolving the effects of acidic aerosols on health, impacts on materials, or acidic seed particle chemistry, such as the competition between $\mathrm{NH}_{3}$ and organic gas uptake to acidic $\mathrm{SO}_{4}^{2-}$ containing particles (Liggio et al., 2011; Liggio and Li, 2013). 

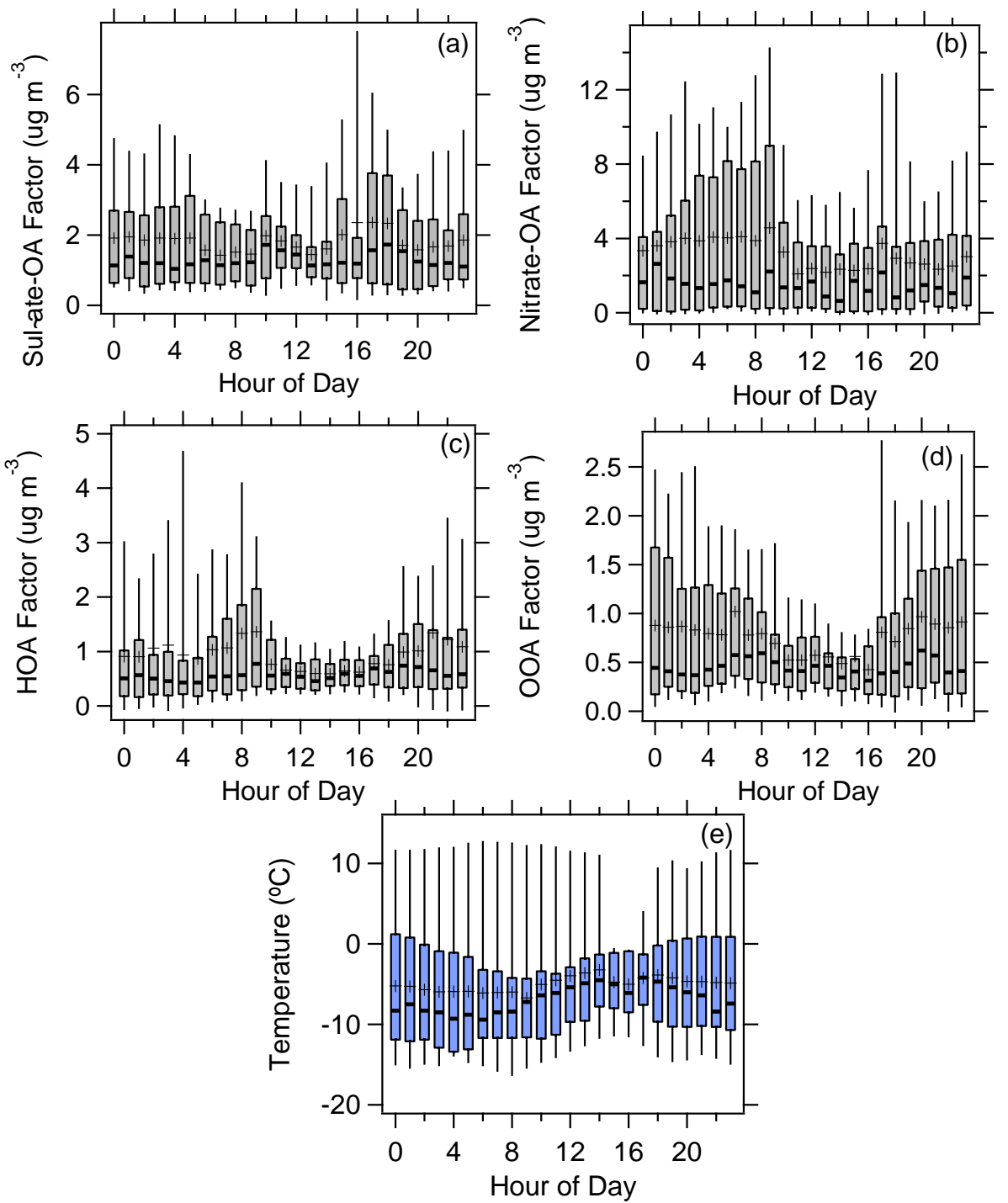

Figure 11. Boxplots of diurnal trends for the Sulfate-OA (a), Nitrate-OA (b), HOA (c), and OOA (d) factors, from the PMF Full MS analysis, along with temperature (e). Boxes indicate interquartile ranges, horizontal lines indicate median hourly values, cross markers indicate hourly means, and whiskers represent the 5th and 95th percentiles. The HOA factor demonstrated a strong diurnal trend consistent with traffic patterns, while the OOA factor demonstrated a trend more consistent with daytime lows and overnight highs. The Nitrate-OA factor showed a minor diurnal trend indicative of more regional contributions as compared to OOA, while the Sulfate-OA factor showed a minimal diurnal trend.

The organic fraction of the Sulfate-OA factor was extracted for comparison with the organic fraction of other factors, as well as published organic factor MS (Fig. 6). Uncertainty in the organic fraction was assessed through rotational analysis, and was found to be low, suggesting that these organics were reasonably rotationally fixed. The organic composition amongst factors extracted using the $\mathrm{PMF}_{\text {Full MS }}$ analysis was assessed against that from other studies. Only one of the past three similar studies, that of Sun et al. (2012), was sufficiently similar for comparison; Chang et al. (2011) involved Arctic aerosol, and the analysis by Crippa et al. (2013b) only involved the organics and
$\mathrm{SO}_{4}^{2-}$. The Sulfate-OA factor contained $21 \%$ of organics by mass, accounting for $16 \%$ of the total measured organics; interestingly, this value was the same as that produced in the analysis by Sun et al. (2012). Although both of these studies were conducted in highly urban environments, such an agreement is interesting, considering that different organic factors were found. Compared to other factors from this study with significant organic content (i.e., $>15 \%$ by mass), the Sulfate-OA factor organics were most similar to typical OOA mass spectra, and were the most highly oxidized according to the associated $\mathrm{F} 44$ and $\mathrm{O} / \mathrm{C}$ ratios. The $\mathrm{F} 44$ metric (fractional contribution of $m / z 44$ within the organic 
MS) has been used in PMF Org MS studies to assess the degree of oxygenation of OOA factors, as it primarily represents $\mathrm{CO}_{2}^{+}$, the most prevalent oxygenated fragment within the organic MS. An empirical relation between F44 and the atomic oxygen to carbon ratio $(\mathrm{O} / \mathrm{C})$ within a PMF-OOA factor has been developed based on a collection of laboratory and field study data (based on PMF ${ }_{\text {Org MS }}$ analyses) (Aiken et al., 2008), and has been used to estimate the $\mathrm{O} / \mathrm{C}$ ratio for similar factors in other studies, including previous PMF studies of combined organic and inorganic mass spectra (Chang et al., 2011; Sun et al., 2012; Crippa et al., 2013b). An F44 of 0.15 (estimated $\mathrm{O} / \mathrm{C}=0.65$ ) was calculated for this factor, the highest value from this study, and consistent with the average values obtained for OOA for two-component OA data sets (i.e., HOA and OOA) across the Northern Hemisphere $(\mathrm{F} 44=0.14 \pm 0.04, \mathrm{O} / \mathrm{C}=0.62 \pm 0.15$, mean $\pm 1 \sigma)(\mathrm{Ng}$ et al., 2010).

Many previous AMS PMF studies have shown that a high degree of correlation exists between $\mathrm{SO}_{4}^{2-}$ and OOA (Lanz et al., 2008; Ulbrich et al., 2009; Slowik et al., 2010; Richard et al., 2011). However, this analysis has been useful for subapportionment of the oxygenated organic fraction of OA to different factors, as the Sulfate-OA factor was found to contain a notable fraction $(31 \%)$ of the total OOA (defined here as the proportion of $m / z 44$ signal apportioned to this factor, excluding the Amine factor) and, in this case, the most oxidized fraction of the OOA. The higher degree of oxygenation exhibited by this factor is consistent with its regional origins from the south and a longer atmospheric lifetime. Although the mixing state of particles associated with this factor cannot be positively deduced from these data, two extremes exist. Either this factor mainly represents externally mixed OOA and $\left(\mathrm{NH}_{4}\right)_{2} \mathrm{SO}_{4}$ particles that exhibit similar temporality due to regional transport, or it represents internally mixed $\left(\mathrm{NH}_{4}\right)_{2} \mathrm{SO}_{4}$ particles coated by lower-volatility SOA during regional transit.

In summary, the Sulfate-OA factor was neutralized and associated with the most highly oxygenated organics. Crossapportionment of the most oxygenated organics measured during this campaign further reinforced this factor's aged, regional nature. While the Sulfate-OA factor appears to be dominated by regional transport of neutralized ammonium sulfate, minor contributions from more local, primary $\mathrm{SO}_{4}^{2-}$ sources were present as well.

\subsubsection{Nitrate-OA factor}

The Nitrate-OA factor time series and mass spectrum are shown in Figs. 4 and 5, respectively, and its contribution to total mass is shown in Fig. 7. Of all the factors, it contributed most to the sub-micron PM mass, with an average mass concentration of $3.19 \mu \mathrm{g} \mathrm{m}^{-3}$ (45\%). Significant accumulation was observed towards the end of the campaign, when a severe nitrate episode occurred, and this factor's mass alone exceeded $20 \mu \mathrm{g} \mathrm{m}^{-3}$.
Deconvolution of the Nitrate-OA factor into its component species (Table 2) shows that it was mostly composed of $\mathrm{NH}_{4}^{+}$ and $\mathrm{NO}_{3}^{-}$(78\% by mass). However, other species such as organics and $\mathrm{SO}_{4}^{2-}$ also comprise a significant mass fraction (16 and $6 \%$, respectively). As with the Sulfate-OA factor, the Nitrate-OA factor demonstrated identical organic composition to the $\mathrm{NO}_{3}-\mathrm{OA}$ factor found in the study by Sun et al. (2012). That both of these largely inorganic factors were highly similar to another study conducted in New York City is a possible indication of consistent internal and/or external mixing between these combined inorganic and organic species in these types of inorganic factors. The dominance of ammonium nitrate in this factor's mass spectrum was confirmed by a high correlation with published $\mathrm{NH}_{4} \mathrm{NO}_{3}$ standard spectra $\left(r^{2}=0.96\right)$, with peaks at $m / z 17,18,30$, and 46 (Hogrefe et al., 2004). Comparison with $\mathrm{NH}_{4} \mathrm{NO}_{3}$ calibration mass spectra showed that it also compared well, although the factor's $m / z 30$ to 46 ratio was $19 \%$ higher than the calibration mass spectrum, which was likely due to the presence of organics. The Nitrate-OA factor contained $20 \%$ of the total measured organics during the campaign, or $31 \%$ of the oxidized organics (as defined by the fraction of $m / z 44$ apportioned to this factor). The nitrate-bound organics displayed the second-highest F44 (0.12) of all the factors from the $\mathrm{PMF}_{\text {Full MS }}$ analysis. The F44 of 0.12 corresponded to an estimated $\mathrm{O} / \mathrm{C}=0.54$, which, when compared to $\mathrm{OA}$ components from $\mathrm{PMF}_{\text {Org MS }}$ studies, falls between typical values for OOAI and OOAII, indicating moderately oxidized organics (Ng et al., 2010). Several previous $\mathrm{PMF}_{\text {Org MS }}$ studies have found an association between $\mathrm{NO}_{3}^{-}$and OOAII, suggestive of temperature-dependent volatility (Lanz et al., 2007; Ulbrich et al., 2009). The diurnal trend for the Nitrate-OA factor partly suggests semi-volatile behavior, due to a slight inverse relationship with temperature (Fig. 11b and e); however, slightly higher nighttime values may also be associated with decreased mixing. As a stronger inverse relationship was noted for the OOA factor than for Nitrate-OA, it was likely that the Nitrate-OA factor was likely more regionally influenced. This was reinforced by an $m / z 44$ to 43 ratio of 1.5 , which was lower than that for the Sulfate-OA factor, yet still higher than that expected for OOAII. The extent of neutralization shows that the ratio of cations to anions was near unity (1.04), suggestive of a reasonably neutral factor. FPeak rotational analysis demonstrates that the Nitrate-OA factor appears rotationally fixed (Fig. S2.5 in the Supplement).

Sources of $\mathrm{NH}_{4} \mathrm{NO}_{3}$ precursor gases (i.e., $\mathrm{NH}_{3}$ and $\mathrm{NO}_{\mathrm{x}}$ ) in the Windsor region are abundant: constant vehicle traffic, in large part from the nearby border crossing, provides a constant supply of $\mathrm{NO}_{\mathrm{x}}(38.0 \pm 35.0 \mathrm{ppb})$, as well as minor contributions of $\mathrm{NH}_{3}$ (Li et al., 2006; Godri et al., 2009). While the Windsor-Detroit area may not comprise as significant a source region for $\mathrm{NH}_{3}$ as rural agricultural areas, many point industrial (e.g., a wastewater reclamation plant) and diffuse 
(e.g., traffic, population) sources do emit large quantities of $\mathrm{NH}_{3}$. According to Environment Canada's NAPS monitoring network, $\mathrm{NH}_{3}$ levels are lowest in wintertime in Windsor, yet are still detectable: using the multi-year average $\mathrm{NH}_{3}$ wintertime concentration measured by ion chromatography, the average wintertime $\mathrm{NH}_{3}$ concentration in downtown Windsor between 2004 and 2007 was $0.5 \pm 0.6 \mathrm{ppb}$, which exceeds the $0.1 \mathrm{ppb}$ detection limit for this analytical method. Figure $11 \mathrm{~b}$ presents the diurnal trend for the Nitrate-OA factor. Noted along with a slight diurnal profile that was likely influenced by both temperature (Fig. 11b) as well as reduced mixing overnight and into the early morning, were two small peaks consistent with morning and afternoon rush-hour traffic, at 09:00 and 17:00 LT (local time). These peaks were likely due to $\mathrm{NH}_{4} \mathrm{NO}_{3}$ formation from traffic emissions. A more general traffic contribution to the Nitrate-OA factor was observed by moderate and slight correlations with black carbon (BC) $\left(r^{2}=0.31\right)$ and NO $\left(r^{2}=0.17\right)$, respectively, both traffic tracers.

The geographic origins of the Nitrate-OA factor were explored. The CPF, presented in Fig. 8c, did not reveal any significant directionality; this indicated that this factor was not significantly influenced by any local point sources, but did not discount potential contributions from local diffuse sources such as traffic. The regional nature of the factor was explored through the PSCF (Fig. 9b), which highlighted areas of high source probability to the south and southwest. In comparison with the PSCF from the Sulfate-OA factor, the Nitrate-OA factor also appeared more regionally influenced than the Sulfate-OA factor, yet from less specific source regions. Regional influences are more likely in winter compared to summer in this location, as nitrate can persist and be transported greater distances provided there are cold enough temperatures. In summary, the Nitrate-OA factor contributed most to sub-micron PM mass, was associated with moderately oxidized organics, and was likely attributed to both local and regional sources, with regional contributions likely dominating.

\subsubsection{Chloride factor}

Presented in Figs. 4 and 5, respectively, are the time series and mass spectral profile of the Chloride factor. The chemical composition breakdown for this factor is shown in Fig. 7. Strong peaks observed at $m / z 16$ and 17 indicate significant $\mathrm{NH}_{4}^{+}$content, while peaks at $m / z 35,36,37$ and 38 indicate chloride. The factor appeared to be dominated by $\mathrm{NH}_{4} \mathrm{Cl}$, as it compared well with the NIST mass spectrum for this species $\left(r^{2}=0.71\right)$. The isotopic ratio of $m / z 35$ to $m / z 37$ matched that from the AMS chloride fragmentation pattern (3.09). Application of the AMS fragmentation table to the MS demonstrates that $\mathrm{NH}_{4}^{+}$and $\mathrm{Cl}^{-}$contributed 28 and $27 \%$, respectively, to the mass of this factor; however, other species were also evident, namely $\mathrm{NO}_{3}^{-}(13 \%)$, organics $(13 \%)$, and $\mathrm{SO}_{4}^{2-}(18 \%)$. This study represents the first PMF analysis of AMS mass spectral data to apportion $\mathrm{NH}_{4}^{+}$and $\mathrm{Cl}^{-}$to a unique factor suggestive of mostly ammonium chloride. The extent of neutralization (1.09) shows that this factor was fairly close to neutral, taking into account all identifiable ions (i.e., $\mathrm{NH}_{4}^{+}, \mathrm{Cl}^{-}, \mathrm{NO}_{3}^{-}$, and $\mathrm{SO}_{4}^{2-}$ ), and considering potential PMF error and uncertainty in RIEs.

Interestingly, the factor was composed $13 \%$ by mass of organics (Fig. 6). The most significant organic peaks were $m / z 29,41$, and 55 , and a mass spectral delta pattern with $\Delta=0$ (i.e., $m / z 27,41,55,69$, etc.) was noted (McLafferty and Tureček, 1993). However, despite a distinct delta pattern, the factor showed rotational uncertainty that precluded over-interpretation of the factor's organics. With negative rotations, the $\mathrm{Cl}^{-}$and $\mathrm{NH}_{4}^{+}$content varied only slightly. However, rotation in both the positive and negative direction caused significant changes to the organic fraction delta pattern: negative rotations caused the $\Delta=0$ pattern to decrease and the $\Delta=2$ pattern $(m / z 29,43,57,71$, etc. $)$ to increase, while there was insignificant change in the organic mass spectral profile with positive rotations. As the organic profile and content varied most significantly among all of the Chloride factor components (from 18 to $40 \%$ by mass), the delta pattern could not be used with confidence for factor identification. It should be noted that little uncertainty was observed for the $\mathrm{SO}_{4}^{2-}$ mass fraction of the Chloride factor, indicating that the $\mathrm{SO}_{4}^{2-}$ cross-apportionment was relatively robust. Although the Chloride factor showed the most uncertainty among all PMF factors (Fig. S2.5 in the Supplement), its appearance from five to eight factors suggested it was robust.

The presence of $\mathrm{NH}_{4} \mathrm{Cl}$ aerosol in the atmosphere has previously been noted. Pio and Harrison (1987a, b) performed early experiments to assess the thermodynamic behavior of $\mathrm{NH}_{4} \mathrm{Cl}$ under tropospheric conditions and found that, like $\mathrm{NH}_{4} \mathrm{NO}_{3}, \mathrm{NH}_{4} \mathrm{Cl}$ formation is favored by lower temperatures and higher RH (Pio and Harrison, 1987a, b). The conditions associated with the Chloride factor were examined (i.e., temperature, $\mathrm{RH}$, cloudiness, fog, rain) to determine if rapid meteorological changes triggered gas-to-particle transition. No association could be discerned. However, it should be noted that from 14 January onward, on the whole, the conditions for $\mathrm{NH}_{4} \mathrm{Cl}$ were favorable, with a mean temperature of $-8 \pm 5^{\circ} \mathrm{C}$ and $\mathrm{RH}$ of $73 \pm 13 \%$.

Although not measured directly, particulate $\mathrm{NH}_{4} \mathrm{Cl}$ has been speculated to be present in several settings due to a high correlation between its component species. Perron et al. (2010) have reported $\mathrm{NH}_{4} \mathrm{Cl}$-containing particles in a Swiss Alpine valley setting due to a significant correlation in $\mathrm{NH}_{4}^{+}$and $\mathrm{Cl}^{-}$spikes, with $\mathrm{Cl}^{-}$likely emitted as $\mathrm{KCl}$ during biomass combustion (Perron et al., 2010). In a study in Mexico City, Salcedo et al. (2006) reported large yet shortlived plumes of chloride, which were coincident with spikes in both $\mathrm{NH}_{4}^{+}$and organics; the simultaneous appearance of both $\mathrm{NH}_{4}^{+}$and $\mathrm{Cl}^{-}$indicated $\mathrm{NH}_{4} \mathrm{Cl}$ formation (Salcedo et 
al., 2006). Precursor gases (e.g., $\mathrm{NH}_{3}, \mathrm{HCl}$, and $\mathrm{HNO}_{3}$ ) and their sources are plentiful in this region. Although $\mathrm{NH}_{3}$ is typically the limiting agent in these reactions, in this region, point industrial (e.g., a wastewater reclamation plant) and diffuse (e.g., traffic, population) sources of $\mathrm{NH}_{3}$ are numerous. There are thus two plausible mechanisms for $\mathrm{NH}_{4} \mathrm{Cl}$ formation in the Windsor-Detroit region. In the first case, $\mathrm{NH}_{3}$ could react with primary $\mathrm{HCl}$ that has been emitted directly by anthropogenic sources. According to NPRI and TRI emissions inventories, the largest primary emitter of $\mathrm{HCl}$ in Windsor-Detroit in 2005 was the River Rouge power plant, located $3 \mathrm{~km}$ southwest of the receptor site (Environment Canada, 2013; US EPA, 2013b). However, secondary reactions may lead to $\mathrm{HCl}$ production, and eventually to $\mathrm{NH}_{4} \mathrm{Cl}$ formation as well. It is possible that acidic, ammonia-poor, industrial plumes with sufficient $\mathrm{HNO}_{3}$ content may liberate $\mathrm{HCl}$ from certain sources, which then subsequently repartitions as $\mathrm{NH}_{4} \mathrm{Cl}$ to the particle phase under $\mathrm{NH}_{3}$-rich conditions. Some of these sources include $\mathrm{NaCl}$ particles from road salt and $\mathrm{KCl}$ from biomass burning emissions (including coal combustion and domestic wood burning). Waste incineration has also been identified as a potential source of shortduration, strong chloride events; Moffet et al. (2008a, b) reported $\mathrm{Cl}^{-}$spikes along with spikes in $\mathrm{Zn}$ - and $\mathrm{Pb}$-containing particles measured by ATOFMS in Mexico City (Moffet et al., 2008a, b). These events were attributed to rapid secondary $\mathrm{HCl}$ formation from the reaction of $\mathrm{HNO}_{3}$ with $\mathrm{PbCl}$ and $\mathrm{ZnCl}$ in a waste incineration plume. All of these sources were likely in this study: as mentioned previously, there are several coal plants near the site, and a waste incinerator is located to the northwest. Furthermore, given the wintertime conditions, domestic wood burning was prevalent in the region.

Examination of the CPF (Fig. 8d) and PSCF (not shown) did not provide any additional information with respect to local or regional source origins. However, the concurrent appearance of sharp spikes in $\mathrm{Cl}^{-}$and $\mathrm{SO}_{4}^{2-}$ (Fig. 3), and moreover the apportionment of significant $\mathrm{SO}_{4}^{2-}$ to this factor, suggested an association with industrial emissions. Both of these spikes corresponded to a $230-250^{\circ}$ wind direction, consistent with coal plants to the west-southwest. Despite these spikes having been partially captured by their respective, reasonably neutralized PMF factors, the $\mathrm{Cl}^{-}$and $\mathrm{SO}_{4}^{2-}$ observed in these spikes were likely not well neutralized, as concurrent spikes in $\mathrm{NH}_{4}^{+}$at these times were not as strong as those observed for its counter-ions. Any available $\mathrm{NH}_{3}$ at this time was likely partitioned as $\left(\mathrm{NH}_{4}\right)_{2} \mathrm{SO}_{4}$ first, because $\left(\mathrm{NH}_{4}\right)_{2} \mathrm{SO}_{4}$ formation should be thermodynamically more favorable than $\mathrm{NH}_{4} \mathrm{Cl}$ formation under the given meteorological conditions. As such, while the Chloride factor appeared reasonably close to neutral on the whole, there was likely some variation in acidity that was not captured by this factor, as more acidic particles appeared to be present during the spikes. Furthermore, the rotational uncertainty determined through FPeak analysis may have been an indication of the more dynamic nature of this factor's components. In summary, the Chloride factor was most likely associated with local atmospheric processing, whereby ammonium chloride secondary aerosol formed rapidly in-plume from the reaction of $\mathrm{NH}_{3}$ and $\mathrm{HCl}$ emissions. The source of $\mathrm{HCl}$ emissions may have been primary emissions from an industrial facility, and/or it may have formed from secondary reactions.

\subsubsection{HOA factor}

A hydrocarbon-like organic factor (HOA) was extracted by PMF, and its time series and mass spectral profile are presented in Figs. 4 and 5, respectively. The factor's chemical composition is shown in Fig. 7. Accounting for $0.94 \mu \mathrm{g} \mathrm{m}^{-3}$ or $13 \%$ of the sub-micron PM mass during the campaign, the HOA factor represented the third-largest contributor to submicron PM mass. Delta patterns of $\Delta=0$ and $\Delta=2$ were observed in the mass spectral profile, most likely corresponding to alkanes and $\mathrm{H}_{2}$-neutral losses from alkyl fragments and/or alkenes, respectively (McLafferty and Tureček, 1993; Zhang et al., 2005). The extracted HOA factor was similar to those from the Pittsburgh fall of 2002 (Ulbrich et al., 2009) and Zurich winter of 2006 (Lanz et al., 2008) studies, with $r^{2}$ values of 0.56 and 0.66 , respectively.

Deconvolution of the HOA MS into organic and inorganic species was performed using the AMS fragmentation table. Contributions from $\mathrm{NH}_{4}^{+}(5 \%)$ and $\mathrm{NO}_{3}^{-}(9 \%)$ were noted, indicating that this factor was likely mixed with $\mathrm{NH}_{4} \mathrm{NO}_{3}$. FPeak rotational analysis shows that, although the contributions of these species were moderate, their variation with rotation precluded their over-interpretation (Fig. S2.5 in the Supplement). A less-than-plausible extent of neutralization of 1.62 also served to highlight the rotational ambiguity associated with the inorganics, although this uncertainty could be a result of low overall inorganic contributions. With an organic composition of $85 \%$, it was not as similar to the HOA factor found in Sun et al. (2012) (97\%) as it was for other factors.

HOA is often referred to as a surrogate for fossil fuel combustion emissions, with traffic cited as the most significant source contributor (Aiken et al., 2008). The same can be said for this study; moderate $r$ values of 0.48 and 0.64 were found between the HOA factor with $\mathrm{BC}$ and $\mathrm{NO}$, respectively, pollutants that are typically associated with relatively fresh traffic emissions. The HOA factor also displayed moderate and slight correlations with $\mathrm{CO}\left(r^{2}=0.41\right)$, particle number concentration $\left(r^{2}=0.21\right)$, and aromatic hydrocarbons measured by PTR-MS, such as benzene $\left(m / z 79, r^{2}=0.43\right)$, toluene $\left(m / z 93, r^{2}=0.32\right), C_{2}$-benzene $\left(m / z 107, r^{2}=0.58\right)$, and $\mathrm{C}_{3}$-benzene $\left(m / z 121, r^{2}=0.54\right)$, which are also typically associated with primary anthropogenic emissions such as traffic (Vlasenko et al., 2009). Distinct rush hour peaks in the morning (05:00-09:00 LT) and evening (18:00-22:00 LT) further supported source attribution to traffic emissions 
(Fig. 11c). The CPF for the HOA factor provides modest support for a traffic source, as excursions in this factor were moderately associated with the northeast wind sector $(0-$ $\left.90^{\circ}\right)$, consistent with higher traffic density from the international border crossing (Fig. 8e). While general circulation traffic is also likely to be a significant contributor to the HOA factor, many industrial operations in the region combust fossil fuels in their processes, for instance heavy machinery used for onsite material transport. As such, other sources may also contribute to this factor. The HOA factor thus represented primary organic aerosol emissions, with its most significant contributions likely emitted from traffic.

\subsubsection{OOA factor}

A factor consistent with oxygenated organic aerosol (OOA) was extracted using PMF Full MS, and its time series and MS are presented in Figs. 4 and 5, respectively. On average, the OOA factor comprised $0.76 \mu \mathrm{g} \mathrm{m}^{-3}$ or $11 \%$ of the submicron PM mass. The fragmentation table was applied to this factor to decouple the inorganic and organic species for species-based mass spectral and temporal examination. The only other species associated with this factor was $\mathrm{NO}_{3}^{-}$ (7\% by mass). While the OOA factor represented the lowest F44 compared to Sulfate-OA and Nitrate-OA (F44 = 0.09), it contained the highest fraction of oxygenated organic aerosol, as $35 \%$ of $m / z 44$ was apportioned to this factor. The robustness of the factor mass spectrum was examined using FPeak analysis. It was found that rotations caused the minor $\mathrm{NO}_{3}^{-}$concentration to vary (Fig. S2.5 in the Supplement). With a lack of neutralizing species (i.e., $\mathrm{NH}_{4}^{+}$) present, the nitrate contribution may have been attributed to model error. In examining the robustness of the F44 content through FPeak analysis (Table S2.1 in the Supplement), it varied only slightly, suggesting minor rotational ambiguity with respect to the oxygenated organic fragments. In terms of organic composition, this factor's organic composition (93\%) was most comparable to the LV-OOA factor from Sun et al. (2012), which comprised $94 \%$ organics.

Comparing this F44 value with previous studies, it is apparent that the F44 observed in the OOA factor in this study is lower than others from two-component organic results $(\mathrm{Ng}$ et al., 2010). This observation highlights a distinct difference in $\mathrm{PMF}_{\mathrm{Org}}$ MS vs. PMF Full MS. Typically, the contribution of $m / z 44$ to the total organic spectrum is highest in the OOA factor when PMF is applied to the organic MS only. However, in this study it represents the third-most oxygenated organic component among the PMF factors, yet the highest contributor to oxygenated organic aerosol. Compared with mass spectral profiles from other studies, this OOA factor more closely resembled semi-volatile OOAII factors, instead of highly oxygenated OOAI factors, given the comparatively low $m / z 44 / 43$ ratio. The diurnal trend provided further insight into the nature of the OOA factor (Fig. 11d). It can be seen that this factor was significantly higher overnight than during daylight hours, suggesting either buildup in concentration in the nighttime boundary layer, or semi-volatile nighttime gas-to-particle partitioning. The latter was suspected, as lower concentrations were observed on warmer nights, suggestive of a temperature-volatility concentration dependence. In addition, the OOA factor exhibited a stronger anti-correlation with temperature than the Nitrate-OA factor $(r=-0.26)$, suggesting that temperature played a greater role in explaining the variability in the OOA factor than in the Nitrate-OA factor. This was evident in increased contributions in the OOA factor mid-way through to the end of the campaign, when the air was colder. These results show that less oxygenated, and thus likely more local and semi-volatile OOA, appeared to be a significant fraction of the total oxygenated organic aerosol.

The moderately oxidized and semi-volatile behavior of the OOA factor was further demonstrated through the highest correlation between all factors with acetaldehyde $\left(r^{2}=0.31\right)$, a VOC with an atmospheric lifetime of less than a day. Slowik et al. also report observing high correlations between a semi-volatile OOAII factor and acetaldehyde in Toronto, Ontario (Slowik et al., 2009), and a similar conclusion can be drawn here that this factor's variability is influenced by both the oxidation timescale as well as gas-particle partitioning. Ultimately, this factor more closely resembles OOAII rather than OOAI.

The geographic origins of the OOA factor were investigated by both CPF and PSCF. The CPF, shown in Fig. 8f, shows a similar result as was found for the HOA factor, with a moderate association with emissions to the northeast, suggestive of contributions from traffic. However, on the whole, no strong directionality was observed, supporting local oxidation of organic aerosol. The PSCF for this factor was also generated (not shown), although no distinct source regions could be identified, reinforcing the notion that transport was not responsible for the temporal behavior of OOA in Windsor's wintertime air. Hence, the OOA factor mainly represented local atmospheric processing, and appeared to be characterized by less oxygenated, semi-volatile organic aerosol.

\subsection{PMF Full MS vs. PMF Org MS $_{\text {M }}$}

As only two other studies to date have performed PMF on the complete or near-complete MS, the following section investigates the effect of including both inorganics and organics in the analysis. The two- to six-factor solutions from $\mathrm{PMF}_{\text {Org MS }}$ were examined and compared to the six-factor $\mathrm{PMF}_{\text {Full MS }}$ solution. Based on the mass spectral profiles and PMF diagnostics, the three-factor solution provided the most physically meaningful results. A two-factor solution generated Amine and OOA factors, and moving to a three-factor solution produced Amine, OOA and HOA factors similar in profile to those from the PMF Full MS analysis. Adding a fourth factor caused the OOA factor to split, leading to 


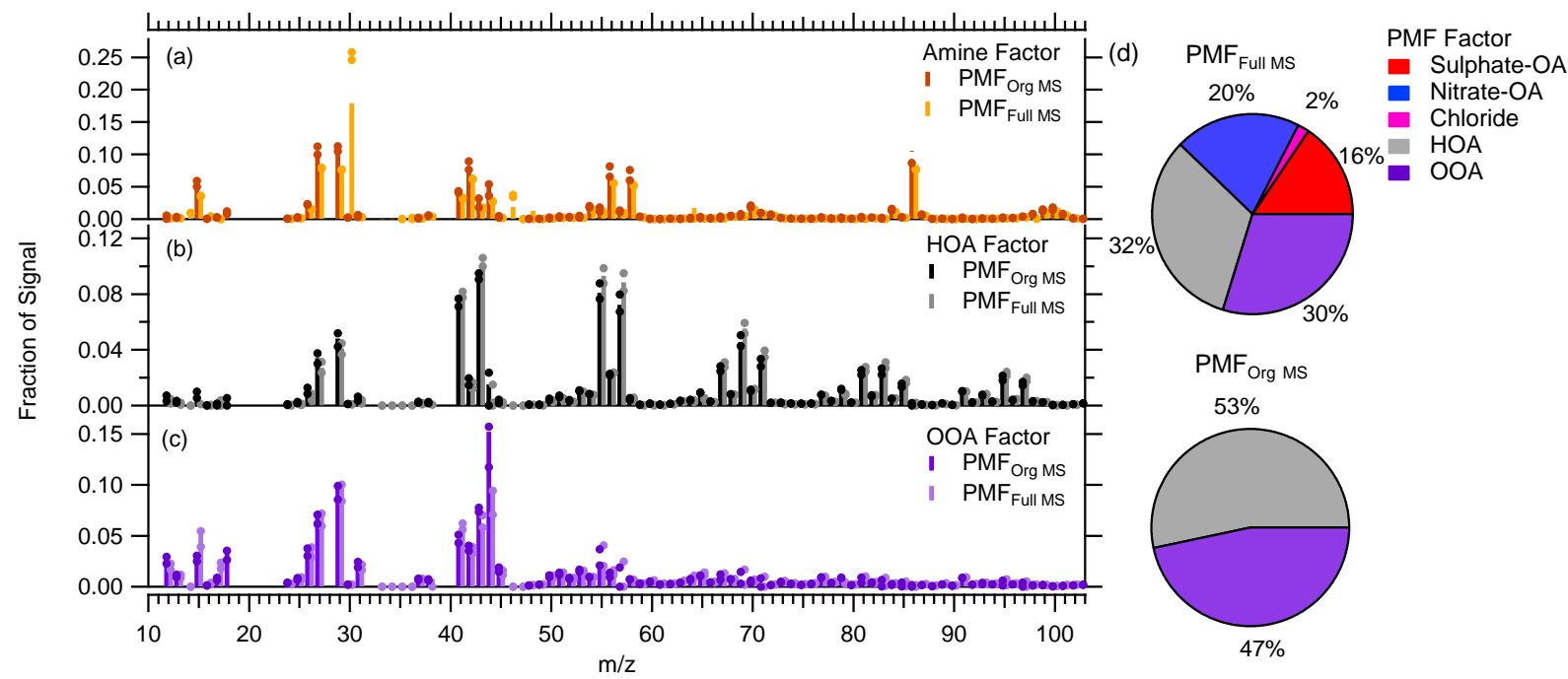

Figure 12. Comparison of factor profiles from the PMF $\mathrm{Org}_{\text {MS }}$ analysis with comparable factors found by PMF of the full mass spectra (a, $\mathbf{b}$, c). The factors are normalized to the total organic fraction signal, except for the Amine factor, which is normalized to the total factor signal. Only minor differences in mass spectra are noted for the HOA factor. The most significant difference for the Amine factor is represented by the addition of the $m / z 30$ peak, and for the OOA factor by the difference in the magnitude of the $m / z 44$ peak. Dots show the range in mass spectral variation from FPeak rotations (-10 and 10). Also shown in (d) is the average factor composition of organics for both the PMF of the full mass spectrum and the organics only.

another with an MS that did not sufficiently resemble any known factors (or any of the organic fractions contained within the factors from the $\mathrm{PMF}_{\text {Full MS solution). The same }}$ applied to the five- and six-factor solutions. A comparison between higher-order solutions from the $\mathrm{PMF}_{\mathrm{Org}} \mathrm{MS}$ analysis and the organic fraction of the $\mathrm{PMF}_{\text {Full MS }}$ six-factor solution showed that they did not contain the same information, indicating that organics were resolved differently between the analyses. As the three-factor solution led to the most physically meaningful results, it was compared with the six-factor

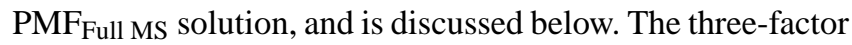
solution justification along with descriptions of the four- to six-factor solutions are presented in the Supplement.

Overall, the organic fraction was mainly split into the HOA and OOA factors, whereby these factors each contributed 53 and $47 \%$, respectively, to the total OA as assessed by the PMF $\mathrm{Prg}_{\mathrm{MS}}$ analysis. This nearly $50: 50$ division between these two organic components was somewhat different than that found in other two-component studies in urban areas, with HOA making a greater contribution (Zhang et al., 2007). Such a difference could possibly be attributed to the significant industrial activity and traffic contributions from the international border crossing.

\subsubsection{Amine factor comparison}

The mass spectra of the Amine factors extracted from the two PMF analyses are compared in Fig. 12a. The most notable difference between the two profiles was the presence of a significant contribution from $m / z 30$ in the $\mathrm{PMF}_{\text {Full MS }}$ analysis. The majority of this signal was removed during extraction of the organic MS, as it is mostly attributed to $\mathrm{NO}^{+}$ in the fragmentation table. Excellent agreement was found between the factor time series $\left(r^{2}=0.99\right)$, indicating that this factor was similarly extracted in the two analyses (Fig. 13a).

The extraction of the Amine factor in this study highlights advantages of applying PMF to the full AMS mass spectrum for unit mass resolution data. Firstly, it can be seen that PMF can provide better resolution of AMS species (i.e., $\mathrm{SO}_{4}^{2-}$, $\mathrm{NO}_{3}^{-}, \mathrm{NH}_{4}^{+}, \mathrm{Cl}^{-}$, and organics) than using the traditional AMS fragmentation scheme, as this method does not presume the nature of chemical species. In this study, the presence of the Amine factor had consequences for the estimation of organics mass concentrations and, ultimately, sub-micron PM mass. A comparison between the AMS-resolved species calculated pre-PMF analysis with those calculated from the factors post-PMF $\mathrm{Full}_{\mathrm{MS}}$ analysis (excluding any mass associated with the Amine factor) is presented in Table 1. It can be seen that organics may have been overestimated by up to $11 \%$. Although the PMF $\mathrm{Prg}_{\mathrm{OS}}$ analysis could be improved by stoichiometrically fixing the contribution of the subtracted inorganic component of $m / z 30\left(\mathrm{NO}^{+}\right)$to $m / z 46$ to include amine ions in the analysis, this was not performed for this analysis, in order to highlight the potential benefits of using the PMF Full Ms method (namely that no a priori assumptions are required regarding the chemical nature of the aerosol). Ultimately, when comparing the pre-PMF sub-micron PM mass to the post-PMF reconstructed mass, it can be seen that the mass may have been overestimated by up to $5 \%$ using the traditional fragmentation scheme. 

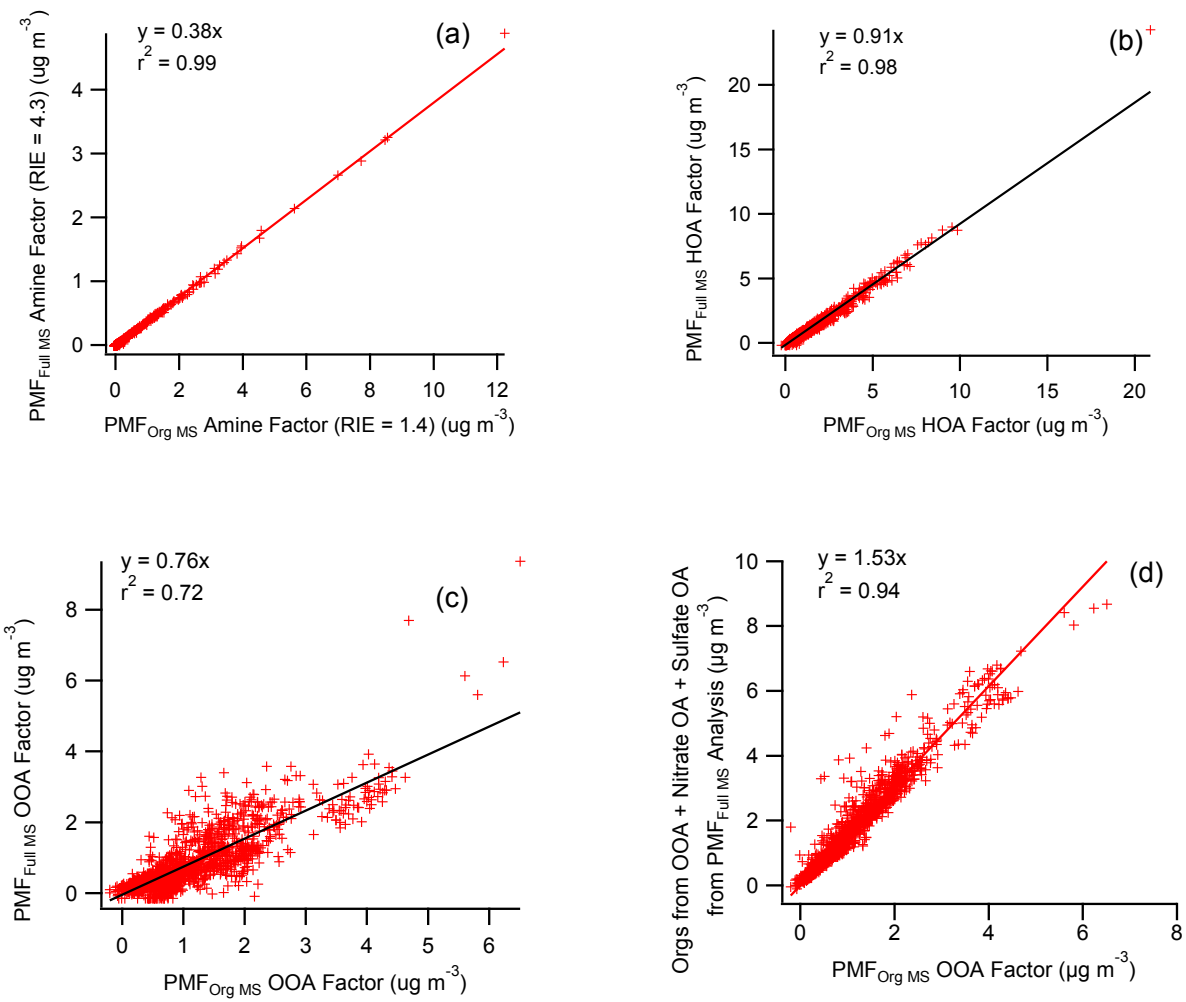

Figure 13. Scatter plots Amine (a), $\mathrm{HOA}(\mathbf{b})$, and OOA (c, d) factors comparing their mass derived from PMF Full MS vs. PMF $\mathrm{Prg}_{\mathrm{MS}}$ analyses. One observation (31 January 2005, 21:00 LT) was removed from the HOA comparison to enhance the fit of the trendline.

Secondly, PMF of the full MS also provided better factor resolution and mass estimates than PMF of the organic MS; with $\mathrm{PMF}_{\mathrm{Org}} \mathrm{MS}$, the organic MS was extracted through application of the organic fragmentation pattern, while in the $\mathrm{PMF}_{\text {Full MS }}$ analysis, the full MS remained as measured, except for subtraction of air and water. Comparison between the $\mathrm{PMF}_{\text {Full MS }}$ and $\mathrm{PMF}_{\text {Org MS }}$ Amine factor time series showed that the mass of the Amine factor from the $\mathrm{PMF}_{\text {Org MS }}$ was 2.6 times greater than that from the $\mathrm{PMF}_{\text {Full MS }}$ analysis. This difference accounted for both the differences in RIE (an effective RIE of 4.3 was assumed in the PMF Full MS analysis) as well as mass contributions from other fragments (namely $m / z 30$, which is typically associated with nitrate, but which may also represent amines). A more direct comparison between the Amine factors resolved in the $\mathrm{PMF}_{\mathrm{Full}} \mathrm{MS}$ and PMF Org MS analyses using $\mathrm{NO}_{3 \text { eq }}^{-}$mass showed that the

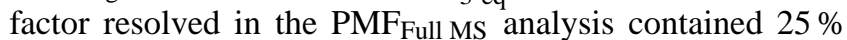
more mass, given inorganic contributions. This suggests that some factors may not be resolved fully using the $\mathrm{PMF}_{\text {Org MS }}$ method. As amine species were assigned as organics in the $\mathrm{PMF}_{\text {Org MS }}$ analysis (with an RIE of 1.4 as opposed to 4.3), it can be seen that errors of up to two and a half times the mass may arise from not considering alternate possibilities for the chemical nature of certain species, which may become clearer through the extraction of the factor's full MS. It is possible that in some cases (e.g., amine-rich areas with amines of higher RIE), this type of error could outweigh other AMS errors such as collection efficiency.

\subsubsection{HOA factor comparison}

Figure $12 \mathrm{~b}$ presents the mass spectral comparison between the HOA factors resolved from PMF analysis of the full MS vs. the organic MS. The HOA factor mass spectra from the two PMF analyses compared very well $\left(r^{2}=0.98\right)$, and good agreement was also found between their time series $\left(r^{2}\right.$ of 0.98 ); a slope of 0.91 for the time series comparison indicated that a portion of this factor had been cross-apportioned to other factors in the full MS analysis (Fig. 13b). Due to minimal differences between MS, it was difficult to distinguish across which factors this HOA was further distributed in the $\mathrm{PMF}_{\text {Full MS }}$ analysis.

\subsubsection{OOA factor comparison}

Figure 12c provides a comparison between the OOA factor profiles extracted in the $\mathrm{PMF}_{\text {Full MS }}$ and $\mathrm{PMF}_{\mathrm{Org} \text { MS analy- }}$ ses. Enhanced cross-apportionment of $m / z 44$ to other factors in the $\mathrm{PMF}_{\text {Full MS }}$ analysis is evident due to the significant difference in the relative contributions of F44 in the OOA factors (i.e.: PMF Full MS F44 $=0.09$; PMF Org MS $_{\text {P }}$ $\mathrm{F} 44=0.15)$. An $\mathrm{F} 44=0.15$ found in the $\mathrm{PMF}_{\mathrm{Org}} \mathrm{MS}$ in this factor is comparable to that found in other studies, also 
indicative that this factor included the highly oxidized organics that were separated into the Sulfate-OA factor in

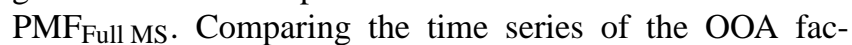
tors between the $\mathrm{PMF}_{\text {Full MS }}$ and $\mathrm{PMF}_{\text {Org MS }}$ analyses, a comparatively low $r^{2}=0.72$ highlighted the fact that some OOA signal was cross-apportioned to inorganic factors in the

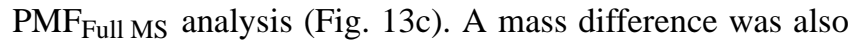
observed between the factors, with the PMF Full MS weighing on average $0.76 \mu \mathrm{g} \mathrm{m}^{-3}$, and the $\mathrm{PMF}_{\text {Org MS measur- }}$ ing on average $1.01 \mathrm{\mu g} \mathrm{m}^{-3}$. A higher mass attributed to the $\mathrm{PMF}_{\mathrm{Org}} \mathrm{MS}$ OOA factor is likely linked to the higher contribution from $m / z 44$. A comparison of just the organic contributions from the factors containing oxidized organic aerosol (Nitrate-OA, Sulfate-OA, and OOA) with the OOA factor from the $\mathrm{PMF}_{\mathrm{Org}} \mathrm{MS}$ three-factor solution showed that the $r^{2}$ was much improved, from 0.72 to 0.94 , with the additional variability from the organic component of these factors (Fig. 13d). A slope slightly higher than unity suggested that the organic aerosol extracted from these three factors was likely not entirely oxidized organic aerosol as defined from the OOA factor from the PMF $\mathrm{Org}_{\mathrm{MS}}$ analysis, and may have contained some less oxidized aerosol as well. This was corroborated by a slope of slightly less than unity for the HOA factor comparison.

Interestingly, the OOA factor could not be split into more OOA factors (i.e., OOAI and OOAII) using PMF analysis of the organics alone. Moving to a four-factor solution resulted in an OOA factor, and another OA factor, which could not be fully justified as its mass spectrum, did not sufficiently resemble any known mass spectra to accept the solution (see the Supplement for further details). It is likely that the inorganics in the $\mathrm{PMF}_{\text {Full MS }}$ analysis provide additional correlational structure to apportion organics more effectively. If moderately oxygenated organics are calculated as those apportioned to the OOA and Nitrate-OA factors, and highly oxygenated organics are those apportioned to the SulfateOA factor, it can be seen that highly oxygenated organics comprise only about a quarter of the total oxygenated organics. With the low prevalence of highly oxygenated organics observed in this campaign, these species may not have carried sufficient weight in the model to result in the splitting of the OOA factor in the PMF $\mathrm{Prg}_{\text {MS }}$ analysis into the OOAI and OOAII types. With the OOA dominated by moderately oxidized organics, the addition of the inorganics-introduced correlational structure for these more minor, more oxidized OAA types could be isolated.

The effect of having performed PMF on the full MS is evident when comparing the time series between $\mathrm{SO}_{4}^{2-}$ and the $\mathrm{PMF}_{\text {Full }} \mathrm{MS}$ and $\mathrm{PMF}_{\mathrm{Org}} \mathrm{MS}$ OOA factors. In many previous studies, particularly in urban locations, the OOA factor from PMF of the organic MS has been highly correlated with $\mathrm{SO}_{4}^{2-}$. Here, an $r^{2}$ of 0.38 was found between $\mathrm{SO}_{4}^{2-}$ and OOA from PMF of the organic fraction. However, following PMF of the full MS, the correlation between the $\mathrm{PMF}_{\mathrm{Full}} \mathrm{MS}$ OOA factor and $\mathrm{SO}_{4}^{2-}$ was markedly lower $\left(r^{2}=0.08\right)$. The PMF Full MS OOA factor thus shows a different temporal character, due to the removal of the highly oxidized contribution. The remaining OOA that characterizes this factor thus more resembles the OOAII typically found when two OOA factors are extracted during $\mathrm{PMF}_{\text {Org MS. Ap- }}$ portionment of organics of varying degrees of oxidation was thus more effectively accomplished through the $\mathrm{PMF}_{\text {Full MS }}$ with the $\mathrm{PMF}_{\mathrm{Org}} \mathrm{MS}$ method, most likely due to correlations with inorganic species of differing atmospheric behavior (e.g., volatility) and origins.

\section{Conclusions}

Six factors were identified through PMF analysis of the full AMS mass spectrum: an Amine factor suspected to be triethylamine nitrate; a Sulfate-OA factor composed of mostly $\left(\mathrm{NH}_{4}\right)_{2} \mathrm{SO}_{4}$ and highly oxidized organics; a Nitrate-OA factor consisting of mostly $\mathrm{NH}_{4} \mathrm{NO}_{3}$ along with moderately oxidized organics; a Chloride factor hypothesized to be mostly $\mathrm{NH}_{4} \mathrm{Cl}$ along with organics and sulfate; an HOA factor classified as mostly primary organics from fossil fuel combustion; and an OOA factor, consisting of moderately oxidized organics.

Factor variability was governed by chemical processing, primary source emissions, and transport. The OOA factor appeared to be influenced mostly by local processing, as it exhibited a strong nighttime diurnal trend consistent with gasto-particle partitioning. While both the Amine and Chloride factors showed temporal trends with brief excursions suggestive of primary source emissions, rapid secondary aerosol formation could not be ruled out in either case. Rapid inplume secondary formation of the Chloride factor was supported by its sporadic appearance and the concurrent appearance with short-lived spikes in $\mathrm{SO}_{4}^{2-}$, consistent with industrial emissions plumes. While the precise mechanism of formation for the Amine factor could not be validated, it was hypothesized to be a result of acid-base reaction of primary triethylamine gaseous emissions with $\mathrm{HNO}_{3}$. Two significant industrial sources of amines located to the southwest of the measurement site were likely the main contributing sources. By contrast, the main determinant for the HOA factor was primary source emissions, given its strong daytime diurnal trend, and high correlations with short-lived traffic-related gases such as NO. Regional transport was most likely the dominant determinant of variability for the Sulfate-OA and Nitrate-OA factors, although local gas-to-particle partitioning also appeared to contribute to the Nitrate-OA factor.

Allowing for PMF to cross-apportion inorganic and organic species between factors led to richer conclusions regarding the potential sources, chemical nature, and behavior of certain factors than would otherwise have been obtained through the application of PMF of organics only. First, cross-apportionment of inorganic species between factors led 
to some enhanced aerosol chemistry conclusions, such as the relative degree of neutralization of co-varying inorganic species. It was found that $\mathrm{NH}_{4}^{+}$was cross-apportioned to the Sulfate-OA, Nitrate-OA and Chloride factors, and on the whole, each of these factors appeared reasonably neutral, at least relative to one another. In an eight-factor solution, a more acidic local sulfate factor appeared. While this solution on the whole could not be justified, it suggests that acidic factors could be extracted in other studies. Second, inclusion of inorganics led to enhanced apportionment of organic aerosol, which in turn led to a better understanding of each factor's degree of oxygenation and chemical nature. For instance, less oxygenated organics were associated with the Chloride and HOA factors, which supported local, primary emissions sources. Inclusion of the inorganics also provided an additional correlational structure to apportion the oxygenated organic fraction, with the most highly oxygenated OA apportioned to the regional Sulfate-OA factor, and the moderately oxygenated OA apportioned to the Nitrate-OA and OOA factors. Using this technique, the resulting OOA factor displayed behavior typical of temperature-dependent gas-to-particle partitioning, while the more oxidized organics contained in the Nitrate-OA and Sulfate-OA factors appeared longer lived, and more associated with regional transport. Without the inclusion of inorganics, the highly oxygenated and moderately oxygenated organics could not be separated effectively.

The methodology used in this study also proved advantageous for extracting atypical factors, and for obtaining more accurate mass quantification for data obtained from a unit mass resolution AMS. In this study, PMF of the full MS resulted in the extraction of the Amine factor, which was only partially extracted using PMF of the organic MS only. A more complete mass spectral profile including inorganic fragments (e.g., $m / z 30$ ) was extracted, which permitted further exploration of the factor's chemical nature. Although its formation mechanism could not be positively validated, the Amine factor was ascertained to have resulted from an acid-base neutralization reaction, and a factor-specific relative ionization efficiency was calculated to provide improved mass estimates. This method was useful for preventing overestimation of certain species, such as nitrate, when the aerosol is influenced by species unaccounted for by the typical AMS analysis scheme. It is likely that this method would be even more useful for HR-ToF-AMS data, due to the ability to understand the chemical nature of atypical factors from high-resolution mass spectra better. In summary, PMF of the full AMS unit mass resolution MS has been shown to be a useful method for obtaining additional insights into the sources and processes governing fluctuations in nonrefractory sub-micron PM chemical composition, in comparison to the PMF of the organics alone.

\section{The Supplement related to this article is available online at doi:10.5194/acp-14-8017-2014-supplement.}

Acknowledgements. These measurements were supported by Environment Canada. Funding for SOCAAR was provided by the Canadian Foundation for Innovation, the Ontario Innovation Trust, and the Ontario Research Fund. M. L. McGuire is grateful to Environment Canada for funding this analysis through the Research Affiliate Program (RAP). The authors gratefully acknowledge the NOAA Air Resources Laboratory (ARL) for the provision of the HYSPLIT transport and dispersion model and/or READY website (http://www.arl.noaa.gov/ready.php) (Draxler and Rolph, 2013; Rolph, 2013) used in this publication. The authors also thank anonymous referees for helpful comments.

Edited by: P. DeCarlo

\section{References}

Aiken, A. C., Decarlo, P. F., Kroll, J. H., Worsnop, D. R., Huffman, J. A., Docherty, K. S., Ulbrich, I. M., Mohr, C., Kimmel, J. R., Sueper, D., Sun, Y., Zhang, Q., Trimborn, A., Northway, M., Ziemann, P. J., Canagaratna, M. R., Onasch, T. B., Alfarra, M. R., Prevot, A. S. H., Dommen, J., Duplissy, J., Metzger, A., Baltensperger, U., and Jimenez, J. L.: O/C and OM/OC ratios of primary, secondary, and ambient organic aerosols with high-resolution time-of-flight aerosol mass spectrometry, Environ. Sci. Technol., 42, 4478-4485, 2008.

Aiken, A. C., Salcedo, D., Cubison, M. J., Huffman, J. A., DeCarlo, P. F., Ulbrich, I. M., Docherty, K. S., Sueper, D., Kimmel, J. R., Worsnop, D. R., Trimborn, A., Northway, M., Stone, E. A., Schauer, J. J., Volkamer, R. M., Fortner, E., de Foy, B., Wang, J., Laskin, A., Shutthanandan, V., Zheng, J., Zhang, R., Gaffney, J., Marley, N. A., Paredes-Miranda, G., Arnott, W. P., Molina, L. T., Sosa, G., and Jimenez, J. L.: Mexico City aerosol analysis during MILAGRO using high resolution aerosol mass spectrometry at the urban supersite (T0) - Part 1: Fine particle composition and organic source apportionment, Atmos. Chem. Phys., 9, 6633-6653, doi:10.5194/acp-9-6633-2009, 2009.

Allan, J. D., Jimenez, J. L., Williams, P. I., Alfarra, M. R., Bower, K. N., Jayne, J. T., Coe, H., and Worsnop, D. R.: Quantitative sampling using an Aerodyne aerosol mass spectrometer: 1. Techniques of data interpretation and error analysis (vol 108, art no 4090, 2003), J. Geophys. Res.-Atmos., 108, 4283, doi:10.1029/2002JD002358, 2003.

Allan, J. D., Delia, A. E., Coe, H., Bower, K. N., Alfarra, M. R., Jimenez, J. L., Middlebrook, A. M., Drewnick, F., Onasch, T. B., Canagaratna, M. R., Jayne, J. T., and Worsnopf, D. R.: A generalised method for the extraction of chemically resolved mass spectra from aerodyne aerosol mass spectrometer data, J. Aerosol Sci., 35, 909-922, 2004.

Allan, J. D., Williams, P. I., Morgan, W. T., Martin, C. L., Flynn, M. J., Lee, J., Nemitz, E., Phillips, G. J., Gallagher, M. W., and Coe, H.: Contributions from transport, solid fuel burning and cooking to primary organic aerosols in two UK cities, Atmos. Chem. Phys., 10, 647-668, doi:10.5194/acp-10-647-2010, 2010.

Anderson, J. O., Thundiyil, J. G., and Stolbach, A.: Clearing the Air: A Review of the Effects of Particulate Matter Air Pollution on Human Health, J. Med. Toxicol., 8, 166-175, 2012. 
Ashbaugh, L. L., Malm, W. C., and Sadeh, W. Z.: A residence time probability analysis of sulfur concentrations at Grand-Canyon National Park, Atmos. Environ., 19, 1263-1270, 1985.

Brook, R. D., Rajagopalan, S., Pope, C. A., Brook, J. R., Bhatnagar, A., Diez-Roux, A. V., Holguin, F., Hong, Y., Luepker, R. V., Mittleman, M. A., Peters, A., Siscovick, D., Smith, S. C., Whitsel, L., and Kaufman, J. D.: Particulate matter air pollution and cardiovascular disease: An update to the scientific statement from the american heart association, Circulation, 121, 23312378, 2010.

Brown, S. G., Lee, T., Norris, G. A., Roberts, P. T., Collett, Jr., J. L., Paatero, P., Worsnop, D. R., van Zyl, P. G., Tiitta, P., and Josipovic, M.: Receptor modeling of near-roadway aerosol mass spectrometer data in Las Vegas, Nevada, with EPA PMF, Atmos. Chem. Phys., 12, 309-325, doi:10.5194/acp-12-309-2012, 2012.

Buset, K. C., Evans, G. J., Leaitch, W. R., Brook, J. R., and ToomSauntry, D.: Use of advanced receptor modelling for analysis of an intensive 5-week aerosol sampling campaign, Atmos. Environ., 40, S482-S499, 2006.

Canagaratna, M. R., Jayne, J. T., Jimenez, J. L., Allan, J. D., Alfarra, M. R., Zhang, Q., Onasch, T. B., Drewnick, F., Coe, H., Middlebrook, A., Delia, A., Williams, L. R., Trimborn, A. M., Northway, M. J., DeCarlo, P. F., Kolb, C. E., Davidovits, P., and Worsnop, D. R.: Chemical and microphysical characterization of ambient aerosols with the aerodyne aerosol mass spectrometer, Mass Spectrom. Rev., 26, 185-222, 2007a.

Canagaratna, M. R., Jayne, J. T., Jimenez, J. L., Allan, J. D., Alfarra, M. R., Zhang, Q., Onasch, T. B., Drewnick, F., Coe, H., Middlebrook, A., Delia, A., Williams, L. R., Trimborn, A. M., Northway, M. J., DeCarlo, P. F., Kolb, C. E., Davidovits, P., and Worsnop, D. R.: Chemical and microphysical characterization of ambient aerosols with the aerodyne aerosol mass spectrometer, Mass Spectrom. Rev., 26, 185-222, 2007b.

Chang, R. Y.-W., Leck, C., Graus, M., Müller, M., Paatero, J., Burkhart, J. F., Stohl, A., Orr, L. H., Hayden, K., Li, S.-M., Hansel, A., Tjernström, M., Leaitch, W. R., and Abbatt, J. P. D.: Aerosol composition and sources in the central Arctic Ocean during ASCOS, Atmos. Chem. Phys., 11, 10619-10636, doi:10.5194/acp-11-10619-2011, 2011.

Chirico, R., Prevot, A. S. H., DeCarlo, P. F., Heringa, M. F., Richter, R., Weingartner, E., and Baltensperger, U.: Aerosol and trace gas vehicle emission factors measured in a tunnel using an Aerosol Mass Spectrometer and other on-line instrumentation, Atmos. Environ., 45, 2182-2192, doi:10.1016/j.atmosenv.2011.01.069, 2011

Crippa, M., DeCarlo, P. F., Slowik, J. G., Mohr, C., Heringa, M. F., Chirico, R., Poulain, L., Freutel, F., Sciare, J., Cozic, J., Di Marco, C. F., Elsasser, M., Nicolas, J. B., Marchand, N., Abidi, E., Wiedensohler, A., Drewnick, F., Schneider, J., Borrmann, S., Nemitz, E., Zimmermann, R., Jaffrezo, J.-L., Prévôt, A. S. H., and Baltensperger, U.: Wintertime aerosol chemical composition and source apportionment of the organic fraction in the metropolitan area of Paris, Atmos. Chem. Phys., 13, 961-981, doi:10.5194/acp-13-961-2013, 2013a.

Crippa, M., El Haddad, I., Slowik, J. G., Decarlo, P. F., Mohr, C., Heringa, M. F., Chirico, R., Marchand, N., Sciare, J., Baltensperger, U., and Prévôt, A. S. H.: Identification of marine and continental aerosol sources in Paris using high resolution aerosol mass spectrometry, J. Geophys. Res.-Atmos., 118, 1950-1963, 2013b.

Docherty, K. S., Aiken, A. C., Huffman, J. A., Ulbrich, I. M., DeCarlo, P. F., Sueper, D., Worsnop, D. R., Snyder, D. C., Peltier, R. E., Weber, R. J., Grover, B. D., Eatough, D. J., Williams, B. J., Goldstein, A. H., Ziemann, P. J., and Jimenez, J. L.: The 2005 Study of Organic Aerosols at Riverside (SOAR-1): instrumental intercomparisons and fine particle composition, Atmos. Chem. Phys., 11, 12387-12420, doi:10.5194/acp-11-12387-2011, 2011.

Draxler, R. R. and Rolph, G. D.: HYSPLIT (Hybrid Single-Particle Lagrangian Integrated Trajectory) Model access via NOAA ARL READY, available at: http://ready.arl.noaa.gov/hysplit.php, last access: December 2013, NOAA Air Resources Laboratory, Silver Spring, MD, 2013.

Drewnick, F., Hings, S. S., Curtius, J., Eerdekens, G., and Williams, J.: Measurement of fine particulate and gas-phase species during the New Year's fireworks 2005 in Mainz, Germany, Atmos. Environ., 40, 4316-4327, 2006.

Environment Canada: National Pollutant Release Inventory, 2013, downloadable at: http://www.ec.gc.ca/inrp-npri/, last access: December 2013.

Ge, X., Wexler, A. S., and Clegg, S. L.: Atmospheric amines Part I. A review, Atmos. Environ., 45, 524-546, 2011.

Godri, K. J., Evans, G. J., Slowik, J., Knox, A., Abbatt, J., Brook, J., Dann, T., and Dabek-Zlotorzynska, E.: Evaluation and application of a semi-continuous chemical characterization system for water soluble inorganic $\mathrm{PM}_{2.5}$ and associated precursor gases, Atmos. Meas. Tech., 2, 65-80, doi:10.5194/amt-2-652009, 2009.

Gordon, G. E.: Receptor Models, Environ. Sci. Technol., 14, 792800, 1980.

Greim, H., Bury, D., Klimisch, H. J., Oeben-Negele, M., and Ziegler-Skylakakis, K.: Toxicity of aliphatic amines: Structureactivity relationship, Chemosphere, 36, 271-295, 1998.

Hildebrandt, L., Kostenidou, E., Lanz, V. A., Prevot, A. S. H., Baltensperger, U., Mihalopoulos, N., Laaksonen, A., Donahue, N. M., and Pandis, S. N.: Sources and atmospheric processing of organic aerosol in the Mediterranean: insights from aerosol mass spectrometer factor analysis, Atmos. Chem. Phys., 11, 1249912515, doi:10.5194/acp-11-12499-2011, 2011.

Hogrefe, O., Drewnick, F., Lala, G. G., Schwab, J. J., and Demerjian, K. L.: Development, operation and applications of an aerosol generation, calibration and research facility, Aerosol Sci. Tech., 38, 196-214, 2004.

Hopke, P. K.: Recent developments in receptor modeling, J. Chemometr., 17, 255-265, 2003.

Huffman, J. A., Docherty, K. S., Aiken, A. C., Cubison, M. J., U1brich, I. M., DeCarlo, P. F., Sueper, D., Jayne, J. T., Worsnop, D. R., Ziemann, P. J., and Jimenez, J. L.: Chemically-resolved aerosol volatility measurements from two megacity field studies, Atmos. Chem. Phys., 9, 7161-7182, doi:10.5194/acp-9-71612009, 2009.

IPCC: Intergovernmental Panel on Climate Change, Fifth Assessment Report, 2013, downloadable at: http://www.ipcc.ch/, last access: December 2013.

Jayne, J. T., Leard, D. C., Zhang, X. F., Davidovits, P., Smith, K. A., Kolb, C. E., and Worsnop, D. R.: Development of an aerosol mass spectrometer for size and composition analysis of submicron particles, Aerosol Sci. Tech., 33, 49-70, 2000. 
Jeong, C.-H., McGuire, M. L., Herod, D., Dann, T., DabekZlotorzynska, E., Wang, D., Ding, L., Celo, V., Mathieu, D., and Evans, G. J.: Receptor Model Based Identification of the Sources of $\mathrm{PM}_{2.5}$ in Canadian Cities, Atmos. Poll. Res., 2, 158-171, 2011.

Jimenez, J. L., Canagaratna, M. R., Donahue, N. M., Prevot, A. S. H., Zhang, Q., Kroll, J. H., DeCarlo, P. F., Allan, J. D., Coe, H., Ng, N. L., Aiken, A. C., Docherty, K. S., Ulbrich, I. M., Grieshop, A. P., Robinson, A. L., Duplissy, J., Smith, J. D., Wilson, K. R., Lanz, V. A., Hueglin, C., Sun, Y. L., Tian, J., Laaksonen, A., Raatikainen, T., Rautiainen, J., Vaattovaara, P., Ehn, M., Kulmala, M., Tomlinson, J. M., Collins, D. R., Cubison, M. J., Dunlea, E. J., Huffman, J. A., Onasch, T. B., Alfarra, M. R., Williams, P. I., Bower, K., Kondo, Y., Schneider, J., Drewnick, F., Borrmann, S., Weimer, S., Demerjian, K., Salcedo, D., Cottrell, L., Griffin, R., Takami, A., Miyoshi, T., Hatakeyama, S., Shimono, A., Sun, J. Y., Zhang, Y. M., Dzepina, K., Kimmel, J. R., Sueper, D., Jayne, J. T., Herndon, S. C., Trimborn, A. M., Williams, L. R., Wood, E. C., Middlebrook, A. M., Kolb, C. E., Baltensperger, U., and Worsnop, D. R.: Evolution of organic aerosols in the atmosphere, Science, 326, 1525-1529, 2009.

Langley, L., Leaitch, W. R., Lohmann, U., Shantz, N. C., and Worsnop, D. R.: Contributions from DMS and ship emissions to $\mathrm{CCN}$ observed over the summertime North Pacific, Atmos. Chem. Phys., 10, 1287-1314, doi:10.5194/acp-10-1287-2010, 2010.

Lanz, V. A., Alfarra, M. R., Baltensperger, U., Buchmann, B., Hueglin, C., and Prévôt, A. S. H.: Source apportionment of submicron organic aerosols at an urban site by factor analytical modelling of aerosol mass spectra, Atmos. Chem. Phys., 7, 15031522, doi:10.5194/acp-7-1503-2007, 2007.

Lanz, V. A., Alfarra, M. R., Baltensperger, U., Buchmann, B., Hueglin, C., Szidat, S., Wehrli, M. N., Wacker, L., Weimer, S., Caseiro, A., Puxbaum, H., and Prevot, A. S. H.: Source attribution of submicron organic aerosols during wintertime inversions by advanced factor analysis of aerosol mass spectra, Environ. Sci. Technol., 42, 214-220, 2008.

Li, Y. Q., Schwab, J. J., and Demerjian, K. L.: Measurements of ambient ammonia using a tunable diode laser absorption spectrometer: Characteristics of ambient ammonia emissions in an urban area of New York City, J. Geophys. Res.-Atmos., 111, D10s02, doi:10.1029/2005JD006275, 2006.

Liggio, J. and Li, S.-M.: A new source of oxygenated organic aerosol and oligomers, Atmos. Chem. Phys., 13, 2989-3002, doi:10.5194/acp-13-2989-2013, 2013.

Liggio, J., Li, S. M., Vlasenko, A., Stroud, C., and Makar, P.: Depression of ammonia uptake to sulfuric acid aerosols by competing uptake of ambient organic gases, Environ. Sci. Technol., 45, 2790-2796, 2011.

Malloy, Q. G. J., Li Qi, Warren, B., Cocker III, D. R., Erupe, M. E., and Silva, P. J.: Secondary organic aerosol formation from primary aliphatic amines with $\mathrm{NO}_{3}$ radical, Atmos. Chem. Phys., 9, 2051-2060, doi:10.5194/acp-9-2051-2009, 2009.

McGuire, M. L., Jeong, C.-H., Slowik, J. G., Chang, R. Y.-W., Corbin, J. C., Lu, G., Mihele, C., Rehbein, P. J. G., Sills, D. M. L., Abbatt, J. P. D., Brook, J. R., and Evans, G. J.: Elucidating determinants of aerosol composition through particle-typebased receptor modeling, Atmos. Chem. Phys., 11, 8133-8155, doi:10.5194/acp-11-8133-2011, 2011.
McLafferty, F. W. and Tureček, F.: Interpretation of mass spectra, vol. xviii, 4th Edn., University Science Books, Sausalito, Calif., 371 pp., 1993.

Middlebrook, A. M., Bahreini, R., Jimenez, J. L., and Canagaratna, M. R.: Evaluation of composition-dependent collection efficiencies for the Aerodyne aerosol mass spectrometer using field data, Aerosol Sci. Tech., 46, 258-271, 2012.

Moffet, R. C., de Foy, B., Molina, L. T., Molina, M. J., and Prather, K. A.: Measurement of ambient aerosols in northern Mexico City by single particle mass spectrometry, Atmos. Chem. Phys., 8 , 4499-4516, doi:10.5194/acp-8-4499-2008, 2008a.

Moffet, R. C., Desyaterik, Y., Hopkins, R. J., Tivanski, A. V., Gilles, M. K., Wang, Y., Shutthanandan, V., Molina, L. T., Abraham, R. G., Johnson, K. S., Mugica, V., Molina, M. J., Laskin, A., and Prather, K. A.: Characterization of aerosols containing $\mathrm{Zn}, \mathrm{Pb}$, and $\mathrm{Cl}$ from an industrial region of Mexico City, Environ. Sci. Technol., 42, 7091-7097, doi:10.1021/es7030483, 2008b.

Mohr, C., DeCarlo, P. F., Heringa, M. F., Chirico, R., Slowik, J. G., Richter, R., Reche, C., Alastuey, A., Querol, X., Seco, R., Peñuelas, J., Jiménez, J. L., Crippa, M., Zimmermann, R., Baltensperger, U., and Prévôt, A. S. H.: Identification and quantification of organic aerosol from cooking and other sources in Barcelona using aerosol mass spectrometer data, Atmos. Chem. Phys., 12, 1649-1665, doi:10.5194/acp-12-1649-2012, 2012.

Murphy, S. M., Sorooshian, A., Kroll, J. H., Ng, N. L., Chhabra, P., Tong, C., Surratt, J. D., Knipping, E., Flagan, R. C., and Seinfeld, J. H.: Secondary aerosol formation from atmospheric reactions of aliphatic amines, Atmos. Chem. Phys., 7, 2313-2337, doi:10.5194/acp-7-2313-2007, 2007.

Ng, N. L., Canagaratna, M. R., Zhang, Q., Jimenez, J. L., Tian, J., Ulbrich, I. M., Kroll, J. H., Docherty, K. S., Chhabra, P. S., Bahreini, R., Murphy, S. M., Seinfeld, J. H., Hildebrandt, L., Donahue, N. M., DeCarlo, P. F., Lanz, V. A., Prévôt, A. S. H., Dinar, E., Rudich, Y., and Worsnop, D. R.: Organic aerosol components observed in Northern Hemispheric datasets from Aerosol Mass Spectrometry, Atmos. Chem. Phys., 10, 46254641, doi:10.5194/acp-10-4625-2010, 2010.

Norris, G., Vedantham, R., Duvall, R., Wade, K., Brown, S., Prouty, J., Bai, S., and DeWinter, J.: EPA Positive Matrix Factorization 4.1 Fundamentals \& User Guide, EPA, Research Triangle Park, North Carolina, 2010.

Paatero, P.: Least squares formulation of robust non-negative factor analysis, Chemometr. Intell. Labor. Syst., 37, 23-35, 1997.

Paatero, P. and Tapper, U.: Analysis of Different Modes of FactorAnalysis as Least-Squares Fit Problems, Chemometr. Intell. Labor. Syst., 18, 183-194, 1993.

Paatero, P. and Tapper, U.: Positive Matrix Factorization - A Nonnegative Factor Model With Optimal Utilization of ErrorEstimates of Data Values, Environmetrics, 5, 111-126, 1994.

Perron, N., Sandradewi, J., Alfarra, M. R., Lienemann, P., Gehrig, R., Kasper-Giebl, A., Lanz, V. A., Szidat, S., Ruff, M., Fahrni, S., Wacker, L., Baltensperger, U., and Prévôt, A. S. H.: Composition and sources of particulate matter in an industrialised Alpine valley, Atmos. Chem. Phys. Discuss., 10, 9391-9430, doi:10.5194/acpd-10-9391-2010, 2010.

Pio, C. A. and Harrison, R. M.: The equilibrium of ammonium chloride aerosol with gaseous hydrochloric acid and ammonia under tropospheric conditions, Atmos. Environ., 21, 1243-1246, 1987a. 
Pio, C. A. and Harrison, R. M.: Vapour pressure of ammonium chloride aerosol: Effect of temperature and humidity, Atmos. Environ., 21, 2711-2715, 1987b.

Pope, C. A. and Dockery, D. W.: Health effects of fine particulate air pollution: Lines that connect, J. Air Waste Manage. Assoc., 56, 709-742, 2006.

Pratt, K. A., Hatch, L. E., and Prather, K. A.: Seasonal volatility dependence of ambient particle phase amines, Environ. Sci. Technol., 43, 5276-5281, 2009.

Rehbein, P. J. G., Jeong, C.-H., McGuire, M. L., Yao, X., Corbin, J., and Evans, G. J.: Cloud and Fog Processing Enhanced Gas-toParticle Partitioning of Trimethylamine, Environ. Sci. Technol., 45, 4346-4352, 2011.

Richard, A., Gianini, M. F. D., Mohr, C., Furger, M., Bukowiecki, N., Minguillón, M. C., Lienemann, P., Flechsig, U., Appel, K., DeCarlo, P. F., Heringa, M. F., Chirico, R., Baltensperger, U., and Prévôt, A. S. H.: Source apportionment of size and time resolved trace elements and organic aerosols from an urban courtyard site in Switzerland, Atmos. Chem. Phys., 11, 8945-8963, doi:10.5194/acp-11-8945-2011, 2011

Rolph, G. D.: Real-time Environmental Applications and Display sYstem (READY) Website available at: http://ready.arl.noaa.gov, last access: December 2013, NOAA Air Resources Laboratory, Silver Spring, MD, 2013.

Salcedo, D., Onasch, T. B., Dzepina, K., Canagaratna, M. R., Zhang, Q., Huffman, J. A., DeCarlo, P. F., Jayne, J. T., Mortimer, P., Worsnop, D. R., Kolb, C. E., Johnson, K. S., Zuberi, B., Marr, L. C., Volkamer, R., Molina, L. T., Molina, M. J., Cardenas, B., Bernabé, R. M., Márquez, C., Gaffney, J. S., Marley, N. A., Laskin, A., Shutthanandan, V., Xie, Y., Brune, W., Lesher, R., Shirley, T., and Jimenez, J. L.: Characterization of ambient aerosols in Mexico City during the MCMA-2003 campaign with Aerosol Mass Spectrometry: results from the CENICA Supersite, Atmos. Chem. Phys., 6, 925-946, doi:10.5194/acp-6-925-2006, 2006.

Silva, P. J., Erupe, M. E., Price, D., Elias, J., Malloy, Q. G. J., Li, Q., Warren, B., and Cocker Iii, D. R.: Trimethylamine as precursor to secondary organic aerosol formation via nitrate radical reaction in the atmosphere, Environ. Sci. Technol., 42, 4689-4696, 2008.

Slowik, J. G., Vlasenko, A., McGuire, M., Evans, G. J., and Abbatt, J. P. D.: Simultaneous factor analysis of organic particle and gas mass spectra: AMS and PTR-MS measurements at an urban site, Atmos. Chem. Phys., 10, 1969-1988, doi:10.5194/acp-10-19692010, 2010.

Stein, S. E.: Mass Spectra, NIST Chemistry WebBook, NIST Standard Reference Database Number 69, National Institute of Standards and Technology, Gaithersburg, MD, 2013.

Sun, Y.-L., Zhang, Q., Schwab, J. J., Demerjian, K. L., Chen, W.N., Bae, M.-S., Hung, H.-M., Hogrefe, O., Frank, B., Rattigan, O. V., and Lin, Y.-C.: Characterization of the sources and processes of organic and inorganic aerosols in New York city with a high-resolution time-of-flight aerosol mass apectrometer, Atmos. Chem. Phys., 11, 1581-1602, doi:10.5194/acp-11-15812011, 2011.

Sun, Y. L., Zhang, Q., Schwab, J. J., Yang, T., Ng, N. L., and Demerjian, K. L.: Factor analysis of combined organic and inorganic aerosol mass spectra from high resolution aerosol mass spectrometer measurements, Atmos. Chem. Phys., 12, 8537-8551, doi:10.5194/acp-12-8537-2012, 2012.
Tan, P. V., Evans, G. J., Tsai, J., Owega, S., Fila, S., Malpica, O., and Brook, J. R.: On-line analysis of urban particulate matter focusing on elevated wintertime aerosol concentrations, Environ. Sci. Technol., 36, 3512-3518, 2002.

Ulbrich, I. M., Canagaratna, M. R., Zhang, Q., Worsnop, D. R., and Jimenez, J. L.: Interpretation of organic components from positive matrix factorization of aerosol mass spectrometric data, Atmos. Chem. Phys. Discuss., 8, 6729-6791, doi:10.5194/acpd-86729-2008, 2008.

Ulbrich, I. M., Canagaratna, M. R., Zhang, Q., Worsnop, D. R., and Jimenez, J. L.: Interpretation of organic components from Positive Matrix Factorization of aerosol mass spectrometric data, Atmos. Chem. Phys., 9, 2891-2918, doi:10.5194/acp-9-2891-2009, 2009.

US EPA: National Emission Inventory (NEI) 2013: Inventory Data: Point Sector Data - ALLNEI HAP Annual, Research Triangle Park, North Carolina, 2013a.

US EPA: Toxics Release Inventory, Washington, D.C., 2013b.

Vlasenko, A., Slowik, J. G., Bottenheim, J. W., Brickell, P. C., Chang, R. Y. W., Maedonald, A. M., Shantz, N. C., Sjostedt, S. J., Wiebe, H. A., Leaitch, W. R., and Abbatt, J. P. D.: Measurements of VOCs by proton transfer reaction mass spectrometry at a rural Ontario site: Sources and correlation to aerosol composition, J. Geophys. Res., 114, D21305, doi:10.1029/2009JD012025, 2009.

Watson, J. G.: Visibility: Science and Regulation, J. Air Waste Manage. Assoc., 52, 628-713, 2002.

Watson, J. G., Chen, L. W. A., Chow, J. C., Doraiswamy, P., and Lowenthal, D. H.: Source apportionment: Findings from the U.S. supersites program, J. Air Waste Manage. Assoc., 58, 265288, 2008.

Zhang, Q., Alfarra, M. R., Worsnop, D. R., Allan, J. D., Coe, H., Canagaratna, M. R., and Jimenez, J. L.: Deconvolution and quantification of hydrocarbon-like and oxygenated organic aerosols based on aerosol mass spectrometry, Environ. Sci. Technol., 39, 4938-4952, 2005.

Zhang, Q., Jimenez, J. L., Canagaratna, M. R., Allan, J. D., Coe, H., Ulbrich, I., Alfarra, M. R., Takami, A., Middlebrook, A. M., Sun, Y. L., Dzepina, K., Dunlea, E., Docherty, K., DeCarlo, P. F., Salcedo, D., Onasch, T., Jayne, J. T., Miyoshi, T., Shimono, A., Hatakeyama, S., Takegawa, N., Kondo, Y., Schneider, J., Drewnick, F., Borrmann, S., Weimer, S., Demerjian, K., Williams, P., Bower, K., Bahreini, R., Cottrell, L., Griffin, R. J., Rautiainen, J., Sun, J. Y., Zhang, Y. M., and Worsnop, D. R.: Ubiquity and dominance of oxygenated species in organic aerosols in anthropogenically-influenced Northern Hemisphere midlatitudes, Geophys. Res. Lett., 34, L13801, doi:10.1029/2007GL029979, 2007.

Zhang, Q., Jimenez, J. L., Canagaratna, M. R., Ulbrich, I. M., Ng, N. L., Worsnop, D. R., and Sun, Y.: Understanding atmospheric organic aerosols via factor analysis of aerosol mass spectrometry: A review, Anal. Bioanal. Chem., 401, 3045-3067, 2011.

Zorn, S. R., Drewnick, F., Schott, M., Hoffmann, T., and Borrmann, S.: Characterization of the South Atlantic marine boundary layer aerosol using an aerodyne aerosol mass spectrometer, Atmos. Chem. Phys., 8, 4711-4728, doi:10.5194/acp-8-47112008, 2008. 